\title{
THE GREAT LOCKDOWN AND THE BIG STIMULUS: TRACING THE PANDEMIC POSSIBILITY FRONTIER FOR THE U.S.
}

\author{
Greg Kaplan \\ Benjamin Moll \\ Giovanni L. Violante \\ Working Paper 27794 \\ http://www.nber.org/papers/w27794 \\ NATIONAL BUREAU OF ECONOMIC RESEARCH \\ 1050 Massachusetts Avenue \\ Cambridge, MA 02138 \\ September 2020
}

We thank Zhiyu $\mathrm{Fu}$ and Brian Livingston for outstanding research assistance. We are grateful to Ralph Luetticke, Ron Milo, Tommaso Porzio, Anna Schrimpf and many (virtual) seminar participants for their useful comments. We have previously presented a preliminary version of this paper under the title "Pandemics According to HANK." The views expressed herein are those of the authors and do not necessarily reflect the views of the National Bureau of Economic Research.

At least one co-author has disclosed a financial relationship of potential relevance for this research. Further information is available online at http://www.nber.org/papers/w27794.ack

NBER working papers are circulated for discussion and comment purposes. They have not been peer-reviewed or been subject to the review by the NBER Board of Directors that accompanies official NBER publications.

(C) 2020 by Greg Kaplan, Benjamin Moll, and Giovanni L. Violante. All rights reserved. Short sections of text, not to exceed two paragraphs, may be quoted without explicit permission provided that full credit, including $(\odot$ notice, is given to the source. 
The Great Lockdown and the Big Stimulus: Tracing the Pandemic Possibility Frontier for the U.S.

Greg Kaplan, Benjamin Moll, and Giovanni L. Violante

NBER Working Paper No. 27794

September 2020

JEL No. E0

\section{ABSTRACT}

We provide a quantitative analysis of the trade-offs between health outcomes and the distribution of economic outcomes associated with alternative policy responses to the COVID-19 pandemic. We integrate an expanded SIR model of virus spread into a macroeconomic model with realistic income and wealth inequality, as well as occupational and sectoral heterogeneity. In the model, as in the data, economic exposure to the pandemic is strongly correlated with financial vulnerability, leading to very uneven economic losses across the population. We summarize our findings through a distributional pandemic possibility frontier, which shows the distribution of economic welfare costs associated with the different aggregate mortality rates arising under alternative containment and fiscal strategies. For all combinations of health and economic policies we consider, the economic welfare costs of the pandemic are large and heterogeneous. Thus, the choice governments face when designing policy is not just between lives and livelihoods, as is often emphasized, but also over who should bear the burden of the economic costs. We offer a quantitative framework to evaluate both trade-offs.

Greg Kaplan

Department of Economics

University of Chicago

1126 E 59th St

Chicago, IL 60637

and NBER

gkaplan@uchicago.edu

Benjamin Moll

London School of Economics

Houghton Street

London WC2A 2AE

United Kingdom

and NBER

b.moll@1se.ac.uk
Giovanni L. Violante

Department of Economics

Princeton University

Julis Romo Rabinowitz Building

Princeton, NJ 08540

and NBER

violante@princeton.edu 


\section{Introduction}

The COVID-19 pandemic has fueled a global health and economic crisis of unprecedented severity. Six months into the pandemic, the death toll in the U.S. is approaching 200,000 and, despite massive fiscal stimulus, we are in the midst of the deepest economic contraction in modern history. Since person-to-person contact is essential for a substantial fraction of the U.S economy to function, and since such close contact allows the virus to spread easily, both fatalities and economic losses are unavoidable.

It is thus not surprising that much of the debate around the appropriate policy response to the pandemic hinges on one question: how large is the trade-off between saving lives and preserving livelihoods? Our goal in this paper is to contribute to this debate by quantifying this trade-off, focusing on the distributional effects of the pandemic and associated policy responses, across different types of workers and households.

Exposure and vulnerability to the pandemic Our analysis builds on the observation that those individuals who are most financially exposed to the pandemic are also the most financially vulnerable.

The key dimension of heterogeneity for economic exposure to the pandemic is occupation. Workers in occupations that both require social interaction, and have little flexibility to work remotely (such as waiters, hairdressers, and dentists), have experienced especially large drops in their earnings. In contrast, the earnings of workers in occupations that produce goods and services that do not require social interactions, and have high flexibility to work from home (such as lawyers, academics, and finance professionals) have been left relatively unscathed.

Whether these different labor market experiences translate into differences in economic welfare depends on households' financial vulnerability. The key dimensions of heterogeneity for vulnerability are the size and composition of household balance sheets, eligibility for government transfers, and the ability to increase labor supply to compensate for the fall in income. Jointly, these factors explain the extent to which losses in income and wealth due to the pandemic translate into a fall in consumption and economic welfare.

Using individual and household-level micro data, we document that those individuals who work in rigid social-intensive occupations tend to have particularly low earnings, wealth and buffers of liquid assets. On the other hand, workers in flexible occupations with low exposure to the social sector tend to have higher earnings, robust balance sheets and enough liquid wealth to weather the storm. This strong positive correlation between economic exposure to the pandemic and financial vulnerability suggests that the effects of the pandemic have been extremely unequal across the population. There is thus a great deal of scope for economic and health policies, with appropriate patterns of redistribution, to both contain the virus and mitigate the economic losses of the most affected households. 
Integrated epidemiological and heterogeneous agent macroeconomic model To evaluate the scope of these possibilities, we integrate an expanded SIR model of virus spread into a heterogeneous-agent incomplete-markets macroeconomic model, which we calibrate to epidemiological, clinical, macroeconomic and cross-sectional data for the U.S. economy.

The epidemiological block of the model consists of a SEIR model à la Kermack and McKendrick (1927) with two additional features: (i) a constraint on ICU (Intensive Care Unit) capacity, which leads to a higher death rate when violated; (ii) feedback from economic behavior to the dynamics of the pandemic that makes the transmission rate of the virus depend endogenously on individual work and consumption choices.

The economic block of the model builds on the heterogeneous-agent incomplete-market literature. In addition to modeling income risk, wealth and portfolio heterogeneity, we introduce a number of new ingredients that are central to understanding the impact of the pandemic and policy responses: (i) three types of goods: regular goods, social goods and home-produced goods; (ii) three types of labor: in the workplace, remote, and home production; and (iii) occupations that differ with respect to their flexibility for remote work, their use in production of regular versus social goods, and how essential they are for providing critical goods and services. These elements are important for capturing household heterogeneity in economic exposure to the pandemic and financial vulnerability. Finally, individuals' disutility from working in the workplace, and their utility from consuming social goods, both depend on the extent of the virus. This feature captures voluntary social distancing behaviors that lead to a fall in economic activity even in the absence of a lockdown.

Pandemic possibility frontier To summarize the trade-offs between health and economic outcomes for different policy alternatives, we advocate the use of a distributional pandemic possibility frontier (PPF). Figure 1 shows an example of a PPF for our baseline experiments in which we vary the length of a workplace and social sector lockdown, with and without fiscal support. Different policy scenarios are represented on the frontier with two cost metrics: (i) deaths due to the virus (horizontal axis), and (ii) economic welfare costs for those alive (vertical axis).

Most existing analyses of the welfare costs of the pandemic or lockdown policies use a single number, such as lost GDP or unemployment, as a summary. In contrast, our heterogeneous agent approach allows us to account for the fact that welfare losses are very unevenly distributed across the population, by computing individual-specific welfare costs. We measure these costs as a compensating variation in terms of liquid wealth: the one-time wealth transfer, expressed as a multiple of each individual's pre-pandemic monthly income, that would make them indifferent in terms of economic outcomes between experiencing the pandemic and associated policy response versus the pre-pandemic steady-state. The distributional PPF reports not only the average welfare cost for each policy scenario, but also the dispersion in these costs. For example, the shaded area in Figure 1 shows the 10th 


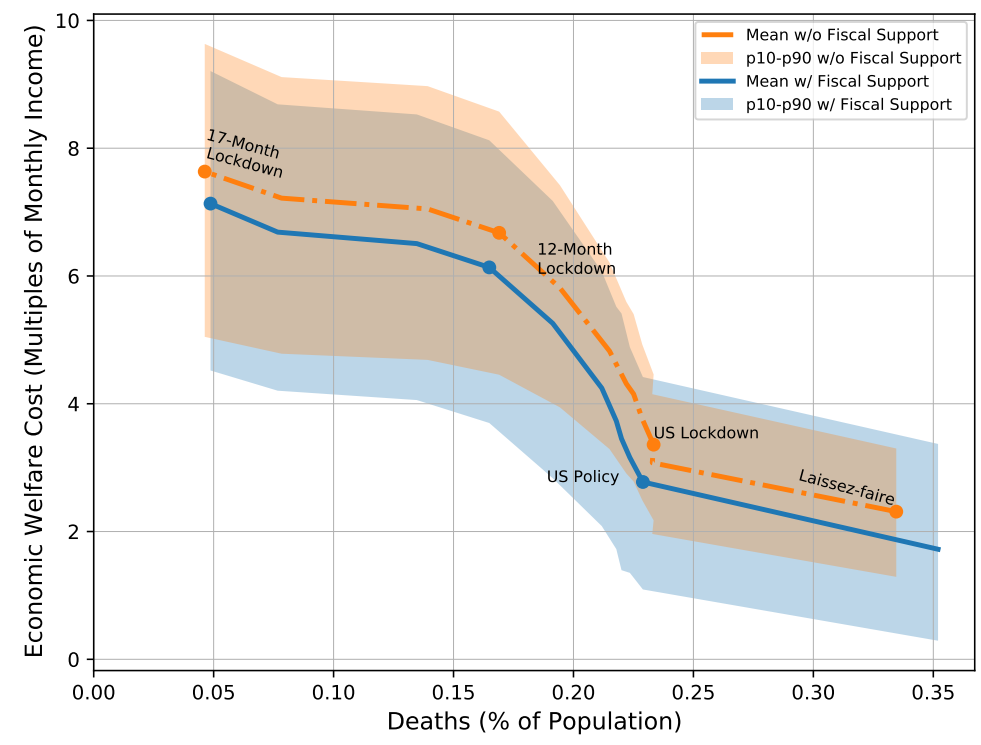

Figure 1: Pandemic Possibility Frontier summarizing our main results. Laissez-faire: no lockdown and no fiscal support. U.S. lockdown: lockdown without fiscal stimulus. U.S. policy: lockdown plus fiscal stimulus. Each point corresponds to lockdowns of different durations.

and 90th percentiles of economic welfare costs, with and without fiscal support

Relative to existing approaches, an important advantage of our frontier is that it allows for a quantitative comparison of different policy scenarios without taking a stand on the monetary value of life. Instead, we present policy makers with a menu of policy options that can be evaluated against subjective indifference curves, and we identify suboptimal policies that lie on the wrong side of the frontier. One of our objectives is to identify policies that shift the frontier inward, thus allowing for the same number of fatalities with lower economic costs, or vice-versa.

Main findings Our first finding is that, for all health and economic policies that we consider, the economic welfare costs are large and very heterogeneous. For example, the point labelled "US Lockdown" in Figure 1 shows that with a 2-month lockdown, the average economic welfare loss is above 3 months of income, and the 90-10 ratio of economic costs is above 2. Even in the laissez-faire scenario without any lockdown or fiscal intervention (point labelled "Laissez-faire"), in which fatalities are highest, the average economic costs of the pandemic are around 2 months of income, also with substantial heterogeneity. This is because individuals react to rising infections and deaths by endogenously reducing both social consumption and supply of workplace hours.

With or without a lockdown, the largest welfare costs accrue to households in the middle of the income distribution. Households at the bottom of the distribution depend largely on 
government transfers and so are less affected, whereas those at the top of the distribution mostly work in flexible jobs. However among those in rigid occupations, the identities of those hit hardest is affected by the lockdown. In the laissez-faire scenario, only workers in social-intensive occupations suffer large earnings drops, whereas under the workplace lockdown, the earnings of workers in all occupations are also hit very hard.

Our second finding is that the slope of the PPF varies tremendously with the length of the lockdown. This finding reconciles conflicting opinions on the existence of a trade-off between lives and livelihoods, on the basis of different views about where exactly we are on the frontier. Two features of the pandemic are critical for this non-linearity: limited ICU capacity and the eventual arrival of a vaccine. The two flatter segments of the frontier correspond to lockdown durations that either reduce the time for which the ICU capacity constraint binds (right portion, shorter lockdowns) or avoid a second wave of infections just before the arrival of the vaccine (left portion, longer lockdowns). The steep section of the frontier reflects the fact that lockdowns of intermediate durations are unnecessarily long if the argument is preventing the ICU constraint from binding (flattening the curve) and not long enough if the argument is preventing a second wave of infections.

Our third finding is that the U.S. fiscal policy response implemented in the Spring of 2020 (CARES Act) succeeded in mitigating economic welfare losses by around $20 \%$ on average, while leaving the cumulative death count effectively unchanged. However, the stimulus package made the economic consequences of the pandemic more unequal. This is because the stimulus package redistributed heavily toward low-income households, while middleincome households gained little from the stimulus package but will face a higher future tax burden. This redistribution, together with the large fraction of hand-to-mouth households in the bottom of the income distribution, allows the model to replicate the somewhat puzzling empirical finding that labor incomes have fallen more for poor households than for rich ones, and have remained persistently low, while consumption expenditures of the poor initially fell by the most but then recovered more quickly than those of the rich (Cox et al., 2020; Chetty et al., 2020).

Our fourth finding concerns alternative policy responses that offer a more favorable tradeoff than blunt lockdowns. We show that exempting workers in social-intensive occupations from the workplace lockdown leads to lower economic welfare costs for a sizable part of the population, for a given fatality rate. An even more effective policy is to impose Pigouvian taxes on social consumption and work in the workplace, with revenues rebated to the workers employed in rigid and social-intensive occupations, respectively. These more targeted policies all generate a flatter average PPF with a more favorable trade-off between lives and livelihoods. However, they come at the cost of more unequal economic welfare losses, a feature which would have to be appropriately managed through fiscal redistribution for these policies to be feasibly implemented in practice. 
When tracing the pandemic possibility frontier for the U.S., we focus our attention on lockdown and fiscal stimulus policies, since these are the health and economic policies that have actually been implemented in the U.S. on a large scale. Additionally, we consider the smart policies described in the preceding paragraph. We do not evaluate some alternative policies that may potentially further flatten or shift inward the PPF, such as contact tracing, widespread testing, border closures and mandatory quarantines. Quantifying how these policies affect the trade-offs that we analyze is an important task for future work.

Related literature The literature on the macroeconomic implications of COVID-19 is already vast and still growing. In existing work, macroeconomists have addressed many dimensions of the complex interaction between the epidemic and the economy, such as: basic calculations of the 'lives vs economy' trade-off (e.g. Hall et al., 2020); externalities in individual distancing decisions and socially optimal lockdowns (e.g. Alfaro et al., 2020; Alvarez et al., 2020; Atkeson, 2020; Eichenbaum et al., 2020; Farboodi et al., 2020; Jones et al., 2020; Krueger et al., 2020; Moser and Yared, 2020; Piguillem and Shi, 2020; Rachel, 2020; Toxvaerd, 2020); smarter and more targeted policies in alternative to indiscriminate lockdowns (e.g. Acemoglu et al., 2020; Akbarpour et al., 2020; Alon et al., 2020b; Azzimonti et al., 2020; Baqaee et al., 2020; Berger et al., 2020; Dorn et al., 2020; Favero et al., 2020; Glover et al., 2020; Gollier, 2020; Grimm et al., 2020); the relative importance of demand and supply shocks (e.g. Baqaee and Farhi, 2020; Brinca et al., 2020; Guerrieri et al., 2020); the long-run implications of the virus for the economy (e.g. Barrero et al., 2020; Kozlowski et al., 2020); the role of fiscal stimulus and monetary policy (e.g. Bayer et al., 2020; Carroll et al., 2020; Coibion et al., 2020a; Elenev et al., 2020; Faria e Castro, 2020; Ganong et al., 2020); the labor market outcomes of different demographic groups (e.g. Adams-Prassl et al., 2020; Alon et al., 2020a; Bick and Blandin, 2020; Brotherhood et al., 2020; Cajner et al., 2020; Coibion et al., 2020b; Gregory et al., 2020; Hur, 2020; Mongey et al., 2020); the empirical dynamics of income and consumption in the aggregate and across the distribution (e.g Carvalho et al., 2020; Chetty et al., 2020; Cox et al., 2020; Hacioglu et al., 2020).

We discuss specific connections to the literature in the main body of the paper. The rest of the paper is organized as follows. Section 2 outlines the model. Section 3 describes the parameterization. Section 4 contains all the model simulations. Section 5 concludes.

\section{Model}

Our model has two building blocks: an epidemiological block and an economic block. The epidemiological block consists of a standard compartmental SEIR model à la Kermack and McKendrick (1927) (see e.g. Hethcote, 2000) with two modifications. First, we introduce an

Intensive Care Unit (ICU) state to capture the possibility that an overwhelmed health care 
system leads to a higher death rate. Second, we include a two-way feedback between the dynamics of the pandemic and individual work and consumption choices.

We model households in the tradition of the heterogeneous-agent incomplete-markets macroeconomics literature. Households face uninsurable idiosyncratic income and health risks, and can hold both liquid and illiquid assets. This asset structure leads to realistic consumption and saving behavior, including a sizable aggregate marginal propensity to consume (MPC). Into this relatively standard framework, we introduce some less standard ingredients that are important for understanding the impact of the pandemic and lockdown policies.

First, households consume three different types of goods: regular goods, social goods and home-produced goods. The defining feature of social goods is that consuming them requires social interaction with other individuals. High social interaction translates into faster transmission of the disease. Examples of social consumption include dining in a restaurant, going to a movie, and traveling by air.

Second, households can supply three types of labor: market work in the workplace (i.e. on-site), market work from home (i.e. remote work), and home production. The presence of these different types of consumption goods and labor services allows us to capture substitution along these margins in response to the pandemic and lockdown.

Third, households work in different occupations, which differ along three dimensions:

(i) Flexibility: In less flexible occupations, remote hours are a poor substitute for workplace hours. This introduces a labor supply effect whereby some occupations' effective hours of labor fall in response to the pandemic or to lockdowns.

(ii) Sectoral Intensity: Some occupations are primarily employed in the production of social goods, while others are primarily employed in the production of regular goods. This introduces a labor demand effect whereby the demand for some occupations' labor services falls in response to the pandemic or to lockdowns.

(iii) Essentiality: Workers in some occupations are permitted to continue working on-site during a lockdown.

The model is set in continuous time and there is no aggregate uncertainty. We focus on perfect-foresight transitional dynamics that follow the unexpected arrival of various combinations of the pandemic, lockdown and fiscal stimulus policies. In our benchmark we assume flexible prices. In Appendix A.3 we consider an extension with price rigidities in which a monetary authority sets the nominal interest rate by operating a monetary policy rule.

\subsection{Epidemiological Model}

The economy is populated by a continuum of individuals with initial population size $\mathcal{N}_{0}=1$. At any point in time, each individual is in one of five health states. $\mathcal{S}_{t}$ individuals are 
susceptible to the disease; $\mathcal{E}_{t}$ are exposed, meaning they have contracted the virus but are not yet infectious (the disease is in the incubation period); $\mathcal{I}_{t}$ are infectious, meaning these are active infections that can spread the virus; $\mathcal{C}_{t}$ are critically ill, meaning they are in intensive care and may ultimately die; and $\mathcal{R}_{t}$ have recovered from the disease. The total population size is $\mathcal{N}_{t}=\mathcal{S}_{t}+\mathcal{E}_{t}+\mathcal{I}_{t}+\mathcal{C}_{t}+\mathcal{R}_{t}$ which declines below one when individuals die of the disease. For future reference, we refer to the vector $\mathbf{e}_{t}=\left[\mathcal{S}_{t}, \mathcal{E}_{t}, \mathcal{I}_{t}, \mathcal{C}_{t}, \mathcal{R}_{t}\right]^{\mathrm{T}}$ as the economy's epidemiological state.

Susceptible individuals contract the virus and become exposed at rate $\beta_{t} \mathcal{I}_{t} / \mathcal{N}_{t}$, where $\mathcal{I}_{t} / \mathcal{N}_{t}$ is the population share of infectious individuals. Exposed individuals become infectious at rate $\lambda_{E}$. Individuals exit the infectious state at rate $\lambda_{I}$, with one of two outcomes: with probability $\chi$ they become critically ill and require ICU care, and with probability $1-\chi$ they recover. Critically ill individuals exit the ICU at rate $\lambda_{C}$, again with one of two outcomes: with probability $P\left(\mathcal{C}_{t}, \mathcal{C}_{\text {max }}\right)$ they die and with probability $1-P\left(\mathcal{C}_{t}, \mathcal{C}_{\max }\right)$ they recover. Because of the ICU constraint, the death probability out of the $\mathcal{C}$ state depends on the number of critically ill patients $\mathcal{C}_{t}$ and the ICU capacity $\mathcal{C}_{\max }$ (more on this below). Finally, recovered individuals may become susceptible again at rate $\lambda_{R}$, which we set to $0 .{ }^{1}$ We summarize these movements in the following continuous-time transition matrix:

$$
\mathcal{A}_{t}=\left[\begin{array}{ccccc}
-\beta_{t} \frac{\mathcal{I}_{t}}{\mathcal{N}_{t}} & \beta_{t} \frac{\mathcal{I}_{t}}{\mathcal{N}_{t}} & 0 & 0 & 0 \\
0 & -\lambda_{E} & \lambda_{E} & 0 & 0 \\
0 & 0 & -\lambda_{I} & \lambda_{I} \chi & \lambda_{I}(1-\chi) \\
0 & 0 & 0 & -\lambda_{C} & \lambda_{C}\left(1-P\left(\mathcal{C}_{t}, \mathcal{C}_{\max }\right)\right) \\
\lambda_{R} & 0 & 0 & 0 & -\lambda_{R}
\end{array}\right]
$$

Individual transitions across health states give rise to a system of differential equations for the economy's epidemiological state, given by

$$
\dot{\mathbf{e}}_{t}=\mathcal{A}_{t}^{\mathrm{T}} \mathbf{e}_{t}, \quad \mathbf{e}_{t}=\left[\mathcal{S}_{t}, \mathcal{E}_{t}, \mathcal{I}_{t}, \mathcal{C}_{t}, \mathcal{R}_{t}\right]^{\mathrm{T}}
$$

This is the standard system of differential equations of a compartmental model written in matrix form. For example, the first, second and third equations read

$$
\dot{\mathcal{S}}_{t}=-\beta_{t} \frac{\mathcal{I}_{t}}{\mathcal{N}_{t}} \mathcal{S}_{t}+\lambda_{R} \mathcal{R}_{t}, \quad \dot{\mathcal{E}}_{t}=\beta_{t} \frac{\mathcal{I}_{t}}{\mathcal{N}_{t}} \mathcal{S}_{t}-\lambda_{E} \mathcal{E}_{t}, \quad \dot{\mathcal{I}}_{t}=\lambda_{E} \mathcal{E}_{t}-\lambda_{I} \mathcal{I}_{t}
$$

Our model features a two-way feedback between economic behavior and the dynamics of the pandemic. To model the feedback from economic behavior to infections we assume that

\footnotetext{
${ }^{1}$ While we set $\lambda_{R}=0$ in most of our exercises, this parameter allows for the possibility of partial, rather than permanent, immunity.
} 
the transmission rate of infections is given by

$$
\beta_{t}=\beta\left(C_{s t}, L_{w t}, t\right)
$$

where $C_{s t}$ is aggregate social consumption and $L_{w t}$ is aggregate workplace hours. The function $\beta$ is increasing in its first two arguments. Social consumption and workplace hours are defined in more detail in the next section. The parameterization of the function $\beta$ is described in Section 3. Other recent macroeconomic analyses of the COVID-19 crisis feature similar reduced-form feedback mechanisms (see e.g. Eichenbaum et al., 2020).

We assume that when the number of critical patients exceeds the fixed ICU capacity $\mathcal{C}_{\max }$, the death probability conditional on being critically ill is higher:

$$
P\left(\mathcal{C}_{t}, \mathcal{C}_{\max }\right)=\delta_{C}+\Delta_{C} \max \left\{\mathcal{C}_{t}-\mathcal{C}_{\max }, 0\right\} / \mathcal{C}_{t}
$$

where $\delta_{C}>0$ is the death probability for those patients who have an ICU bed and $\Delta_{C} \in$ $\left[0,1-\delta_{C}\right]$ is the excess death probability for those patients who do not obtain an ICU bed.

Under these assumptions, COVID-19 deaths evolve as $\dot{\mathcal{D}}_{t}=\lambda_{C} \mathcal{C}_{t} P\left(\mathcal{C}_{t}, \mathcal{C}_{\text {max }}\right)$, where $\mathcal{D}_{t}$ denotes cumulative deaths. Individuals in all health states are also at risk of death from other causes, which occurs at the lower Poisson rate $\delta_{N}$. Each person dying of other causes is replaced by a newborn in the susceptible state. ${ }^{2}$

\subsection{Economic Model}

Individuals The economy is populated by a continuum of individuals, indexed by their holdings of liquid assets $b$, illiquid assets $a$, idiosyncratic labor productivity $z$, occupation $j$ and health status $\mathfrak{h} .{ }^{3}$ Labor productivity follows an exogenous Markov process that we describe in detail in Section 3. At each instant in time $t$, the state of the economy is the joint distribution $\mu_{t}(d a, d b, d z, j, \mathfrak{h})$.

Individuals receive a utility flow $U$ from three types of goods: regular consumption $c_{t}$ (the numeraire), social consumption $s_{t}$ and a home-produced good $h_{t}$. They also receive a disutility flow $V$ from supplying three types of labor: work in the workplace $\ell_{w t}$, remote work $\ell_{r t}$, and labor input into home production $\ell_{h t}$ which produces goods one-for-one, $h_{t}=\ell_{h t}$.

\footnotetext{
${ }^{2}$ In the current draft we also assume that each person dying of COVID-19 is replaced by a newborn in the recovered state. This simplifies computations because it leaves the total population size unaffected. While we do not expect this assumption to affect our conclusions in a quantitatively noticeable fashion (because even without replacing COVID-19 deaths by newborns, the level of the population would not change much in absolute terms), we plan to relax this assumption in later drafts.

${ }^{3}$ Throughout the text, we use the term individuals to describe the unit at which economic decisions are made. We also sometimes interchangeably use the term households, particularly when we bring the model to the data in Section 3. This fuzziness in terminology is due to an inherent tension between the model's economic and epidemiological blocks: while households are the more natural units for economic decision-making, disease transmission occurs at the individual level.
} 
$U$ is strictly increasing and strictly concave in its three inputs. $V$ is strictly increasing and strictly convex. Preferences are time-separable and, conditional on surviving, the future is discounted at rate $\rho \geq 0$ :

$$
\mathbb{E}_{0} \int_{0}^{\infty} e^{-\rho t}\left[U\left(c_{t}, v_{s}\left(\dot{\mathcal{D}}_{t}\right) s_{t}, h_{t}\right)-V\left(v_{\ell}\left(\dot{\mathcal{D}}_{t}\right) \ell_{w t}, \ell_{r t}, \ell_{h t}\right)\right] d t
$$

where the expectation is taken over realizations of idiosyncratic productivity and health shocks and also takes into account life expectancy in different health states. A healthy individual faces a baseline death rate $\delta_{N}$, whereas a critically ill individual faces death rate $P\left(\mathcal{C}_{t}, \mathcal{C}_{\text {max }}\right)$ defined in (4). Because of the law of large numbers, and the absence of aggregate shocks, there is no economy-wide uncertainty.

Both the utility from consuming social goods and the disutility from supplying work in the workplace depend on the state of the pandemic through the terms $v_{s}\left(\dot{\mathcal{D}}_{t}\right)$ and $v_{\ell}\left(\dot{\mathcal{D}}_{t}\right)$ where $\dot{\mathcal{D}}_{t}$ is the excess death rate in the population at time $t$. This formulation allows us to capture, in a reduced-form fashion, the behavioral response of individuals to increasing death rates: as $\dot{\mathcal{D}}_{t}$ rises, the marginal utility of social consumption falls and the marginal disutility of workplace hours increases. The formulation is therefore conceptually similar to the way that feedback from pandemic to behavior is modeled in Farboodi et al. (2020), Eichenbaum et al. (2020) and others. Below we explain how our formulation is closely related to the calculations of the value of statistical life (VSL), a mapping that helps in parameterizing this feedback.

Individuals are employed in different occupations, indexed by $j \in J$. Occupations are imperfect substitutes in production and therefore pay occupation-specific wages $w^{j}$ per efficiency unit of hours worked. An occupation's flexibility is denoted by $\phi^{j} \in[0,1]$, which describes how much less productive are remote hours than workplace hours in that occupation. The labor income of an individual with average efficiency units $z=1$ working in occupation $j$ equals $w_{t}^{j}\left(\ell_{w t}+\phi^{j} \ell_{r t}\right)$. A fully rigid occupation has $\phi^{j}=0$ and a fully flexible occupation has $\phi^{j}=1$.

Individuals can save in liquid assets $b$ and illiquid assets $a$. Assets of type $a$ are illiquid in the sense that individuals incur a cost for depositing into or withdrawing from their illiquid account. We use $d_{t}$ to denote an individual's deposit rate (with $d_{t}<0$ corresponding to withdrawals) and $\chi\left(d_{t}, a_{t}\right)$ to denote the flow cost of depositing at a rate $d_{t}$ for an individual with illiquid holdings $a_{t}$. In equilibrium, the presence of the transaction cost implies that the illiquid asset earns a higher real return than the liquid asset so that $r_{t}^{a}>r_{t}^{b}$. Short positions are not allowed in either asset. 
An individual's asset holdings evolve according to:

$$
\begin{aligned}
\dot{b}_{t} & =\left(1-\tau_{t}\right) w_{t}^{j} z_{t}\left(\ell_{w t}+\phi^{j} \ell_{r t}\right)+r_{t}^{b} b_{t}+T_{t}-d_{t}-\chi\left(d_{t}, a_{t}\right)-c_{t}-p_{t}^{s} s_{t} \\
\dot{a}_{t} & =r_{t}^{a} a_{t}+d_{t} \\
b_{t} & \geq 0, \quad a_{t} \geq 0 .
\end{aligned}
$$

Net liquid savings $\dot{b}_{t}$ are given by the individual's income flow (composed of labor earnings taxed at rate $\tau_{t}$, interest payments on liquid assets, and government transfers $T_{t}$ ) net of deposits into $\left(d_{t}>0\right)$ or withdrawals from $\left(d_{t}<0\right)$ the illiquid account, transaction costs $\chi\left(d_{t}, a_{t}\right)$, and consumption expenditures $c_{t}+p_{t}^{s} s_{t}$. Net illiquid savings $\dot{a}_{t}$ equal interest payments on illiquid assets plus net deposits from the liquid account $d_{t}$.

Individuals differ in their health state $\mathfrak{h}$ which also determines their ability to supply labor. All individuals other than the critically ill can supply labor. Although individuals are in one of five true underlying health states $\mathcal{S}, \mathcal{E}, \mathcal{I}, \mathcal{C}$ and $\mathcal{R}$, we assume that only critically ill $\mathcal{C}$ individuals know their true health state while others cannot distinguish which of the four remaining states $\mathcal{S}, \mathcal{E}, \mathcal{I}$ or $\mathcal{R}$ they are in. This assumption reduces the individual state space from five to two, since we only need to keep track of whether individuals are able to supply labor, which we denote by $\mathfrak{h}=\mathfrak{a}$, or critically ill, $\mathfrak{h}=\mathfrak{c}^{4}$

Individuals that are able to supply labor $(\mathfrak{h}=\mathfrak{a})$ maximize $(5)$ subject to $(6)-(8)$. They take as given the dynamics of the pandemic (2), the equilibrium paths for real wages in different occupations $\left\{w_{t}^{j}\right\}_{t \geq 0}, j=1, \ldots, J$, the real return to liquid assets $\left\{r_{t}^{b}\right\}_{t \geq 0}$, the real return to illiquid assets $\left\{r_{t}^{a}\right\}_{t \geq 0}$, the relative price of social goods $\left\{p_{t}^{s}\right\}_{t \geq 0}$ and taxes and transfers $\left\{\tau_{t}, T_{t}\right\}_{t \geq 0}$. Critically ill individuals $(\mathfrak{h}=\mathfrak{c})$ solve a different problem that is described in Appendix A.2. Rather than choosing consumption optimally the government provides them with fixed amounts of regular and social consumption $\underline{c}$ and $\underline{s}$.

As we explain below, $\left\{r_{t}^{b}\right\}_{t \geq 0},\left\{w_{t}^{j}\right\}_{t \geq 0},\left\{r_{t}^{a}\right\}_{t \geq 0}$ and $\left\{p_{t}^{s}\right\}_{t \geq 0}$ are determined by market clearing conditions for bonds, capital, labor and social goods.

Sectors and occupations There are two production sectors, indexed by $i$ : the regular consumption sector $(i=c)$ and the social sector $(i=s)$. Intermediate producers in each sector produce using capital $K_{i}$ and the labor input of occupation $j, N_{i}^{j}$ :

$$
Y_{i}=Z_{i} N_{i}^{\alpha_{i}} K_{i}^{1-\alpha_{i}}, \quad N_{i}=\left[\sum_{j \in \mathrm{J}}\left(\xi_{i}^{j}\right)^{\frac{1}{\sigma}}\left(N_{i}^{j}\right)^{\frac{\sigma-1}{\sigma}}\right]^{\frac{\sigma}{\sigma-1}}, \quad i=c, s .
$$

The sectoral intensity parameters $\left(\xi_{c}^{j}, \xi_{s}^{j}\right)$ describe the importance of labor from each occupation $j$ for production in each of the two sectors. Importantly, these sectoral intensities

\footnotetext{
${ }^{4}$ One implication of this assumption is that we cannot allow for testing in this version of the model. While somewhat unrealistic, this assumption drastically simplifies computation of individuals' economic decisions.
} 


\begin{tabular}{l|c}
\hline $\begin{array}{l}\text { Occupation } \\
\text { Type }\end{array}$ & Examples \\
\hline Essential & Nurse, Firefighter, Mail carrier, Subway operator \\
C-intensive Flexible & Economist, Writer, Software developer, Accountant \\
C-intensive Rigid & Carpenter, Electrician, Astronomer, Biologist \\
S-intensive Flexible & Sec. school teacher, Therapist, Property manager \\
S-intensive Rigid & Cook, Waiter, Dancer, Travel guide \\
\hline
\end{tabular}

Table 1: Examples of different types of 3-digit occupations grouped by their sectoral intensity and their degree of flexibility (i.e. ability to work remotely). See Section 2.2 for details.

differ across occupations, which implies that some occupations are more intensely employed in the production of social goods than others. Intermediate producers rent capital at rate $r_{t}^{k}$ in a competitive capital market and hire labor at wage $w_{t}^{j}$ in competitive labor markets for each occupations $j$.

Table 1 clarifies the distinction between the flexibility and the sectoral intensity dimensions of occupational heterogeneity. For example, software developers and accountants are occupations with high flexibility and low social intensity, because workers in these occupations can effectively work remotely and are typically employed in sectors that produce goods whose consumption does not involve much social interaction with other individuals. In our simulations of the pandemic and lockdown, neither the demand nor supply of labor in these occupations will be strongly affected. In contrast, waiters and travel guides are occupations in which workers cannot effectively work from home, and are employed in sectors that produce social goods. During the pandemic and lockdown, both demand and supply of labor in these occupations will be strongly affected.

The third dimension of occupational heterogeneity is that some occupations are deemed essential. Our definition of essential occupations are those which cannot be effectively performed remotely (low flexibility), but are not subject to government-mandated work from home orders. Examples of essential occupations include nurses and mail carriers. Although the labor supply of essential occupations is not affected by the lockdown, the pandemic does induce a moderate fall in labor demand for these occupations because some of them are intensive in the social sector. ${ }^{5}$

Monopolistic competition and final goods production In each sector $i=c, s$, a competitive representative final-goods producer aggregates a continuum of intermediate inputs

\footnotetext{
${ }^{5}$ Examples of essential occupations that have seen a sharp fall in demand include health-care occupations not directly involved in the hospitalizations caused by the virus, such as dentists and physical therapists.
} 
indexed by $\omega \in[0,1]$

$$
\Upsilon_{i}=\left(\int_{0}^{1} Y_{i}(\omega)^{\frac{\varepsilon-1}{\varepsilon}} d \omega\right)^{\frac{\varepsilon}{\varepsilon-1}}, \quad i=c, s
$$

where $\varepsilon>0$ is the elasticity of substitution across goods. Cost minimization implies that demand for intermediate good $\omega$ is

$$
Y_{i}(\omega)=\left(\frac{p_{i}(\omega)}{P_{i}}\right)^{-\varepsilon} \Upsilon_{i}, \quad \text { where } \quad P_{i}=\left(\int_{0}^{1} p_{i}(\omega)^{1-\varepsilon} d \omega\right)^{\frac{1}{1-\varepsilon}}, \quad i=c, s
$$

Each intermediate good $\omega$ is produced by a monopolistically competitive producer with production function (9) who takes this demand curve as given. ${ }^{6}$

Investment fund Illiquid assets are equity claims on an investment fund. Thus, at every date $t$ the value of the fund $A_{t}$ equals households' aggregate stock of illiquid assets $\int a d \mu_{t}$. The investment fund owns the economy's capital stock $K_{t}$ and makes the economy's investment decision subject to an adjustment $\operatorname{cost} \Phi\left(\iota_{t}\right)$, where $\iota_{t}$ is the investment rate, i.e. investment as a fraction of the capital stock. The fund also owns shares of the intermediate producers in the regular and social goods sectors $\left(\Theta_{s t}, \Theta_{c t}\right)$ that represent claims on the future stream of monopoly profits $\Pi_{i t}$ in each of the two sectors, $i=c, s$. We denote the price of these shares by $q_{t}^{i}$.

The investment fund solves the problem

$$
A_{0}:=\max _{\left\{\iota_{t}, \Theta_{c t}, \Theta_{s t}\right\}_{t \geq 0}} \int_{0}^{\infty} e^{-\int_{0}^{t} r_{s}^{a} d s}\left\{\left[r_{t}^{k}-\iota_{t}-\Phi\left(\iota_{t}\right)\right] K_{t}+\sum_{i=c, s}\left(\Pi_{i t} \Theta_{i t}-q_{t}^{i} \dot{\Theta}_{i t}\right)\right\} d t
$$

subject to $\dot{K}_{t}=\left(\iota_{t}-\delta\right) K_{t}$ with $K_{0}, \Theta_{c 0}$ and $\Theta_{s 0}$ given. It follows that the optimal investment rate $\iota_{t}$ satisfies $1+\Phi^{\prime}\left(\iota_{t}\right)=q_{t}^{k}$ where $q_{t}^{k}$ is the fund's shadow value of capital; (ii) the value of the fund is given by $A_{t}=q_{t}^{k} K_{t}+q_{t}^{c} \Theta_{c t}+q_{t}^{s} \Theta_{s t}$; and (iii) the illiquid asset return $r_{t}^{a}$ satisfies the no-arbitrage condition

$$
r_{t}^{a}=\frac{r_{t}^{k}-\iota_{t}-\Phi\left(\iota_{t}\right)+q_{t}^{k}\left(\iota_{t}-\delta_{k}\right)+\dot{q}_{t}^{k}}{q_{t}^{k}}=\frac{\Pi_{c t}+\dot{q}_{t}^{c}}{q_{t}^{c}}=\frac{\Pi_{s t}+\dot{q}_{t}^{s}}{q_{t}^{s}} .
$$

This condition implies that the value of equity in each sector is given by $q_{t}^{i}=\int_{t}^{\infty} e^{-\int_{t}^{\tau} r_{s}^{a} d s} \prod_{i \tau} d \tau$ for $i=c, s .^{7}$

\footnotetext{
${ }^{6}$ In equation (9) we ignored dependence of production on $\omega$. This is because all intermediate producers within a sector $i$ are symmetric and therefore make the same production and pricing decisions, and so $Y_{i}(\omega)=Y_{i}, i=c, s$. In our baseline model with flexible prices, the only role of monopolistic competition is that firms charge a positive markup $\frac{\varepsilon}{\varepsilon-1}$ over marginal costs. In Appendix A.3 we consider the case with sticky prices in which case monopolistic competition opens the door to modeling a dynamic price-setting decision subject to price adjustment costs.

${ }^{7}$ In Alves et al. (2020) we formally derive equation (10) in a one-sector model. The extension of the proof
} 
Government The government is the sole issuer of liquid assets in the economy, which are real bonds of infinitesimal maturity $B_{t}^{g}$. It faces exogenous expenditures $G_{t}$ and administers a progressive tax and transfer scheme on individual labor income $w_{t}^{j} z\left(\ell_{w t}^{j}+\phi^{j} \ell_{r t}^{j}\right)$, consisting of a proportional tax rate $\tau_{t}$ and transfers $T_{t}^{j}(a, b, z, \mathfrak{h})$ that can depend on the individual state. We also allow the government to subsidize wage payments and profits at rates $\left(\varsigma_{w t}, \varsigma_{\pi t}\right)$ to capture a potentially important aspect of the fiscal response to the pandemic. The government intertemporal budget constraint reads:

$$
\dot{B}_{t}^{g}+\left(\tau_{t}-\varsigma_{w t}\right) \int w_{t}^{j} z\left[\ell_{w t}^{j}(\cdot)+\phi^{j} \ell_{r t}^{j}(\cdot)\right] d \mu_{t}=G_{t}+\int T_{t}^{j}(\cdot) d \mu_{t}+\varsigma_{\pi t}\left(\Pi_{c t}+\Pi_{s t}\right)+r_{t}^{b} B_{t}^{g} .
$$

Lockdowns Lockdowns are government executive orders that affect the economy in two ways.

1. Lockdowns constrain economic activity in the social goods through bans on dining in and closure of non-essential businesses. We model this component by assuming that the governments limits utilization of capital, i.e. capacity, in the social sector. Hence during the lockdown, the production function (9) in the social goods sector becomes

$$
Y_{s}=Z_{s}\left(\kappa_{s} K_{s}\right)^{\alpha_{s}} N_{s}^{1-\alpha_{s}} \text { with } 0 \leq \kappa_{s} \leq 1
$$

where $\kappa_{s}$ measures the degree of capital utilization allowed by the government.

2. Lockdowns also constrain the supply of workplace hours through stay-at-home orders. We model this component by imposing the additional constraint on household labor supply

$$
\ell_{w}^{j} \leq \kappa_{\ell}^{j}\left(\ell_{w}^{j}+\ell_{r}^{j}\right) \quad \text { with } \quad 0 \leq \kappa_{\ell}^{j} \leq 1
$$

where $\kappa_{\ell}^{j}$ measures the maximum share of work that can be performed in the workplace. $^{8}$

The parameters $\kappa_{s}$ and $\kappa_{\ell}^{j}$ are policy parameters. If $\kappa_{s}=\kappa_{\ell}^{j}=0$ there is a full lockdown: sector $s$ is shut down completely and on-site work is banned. If $0<\kappa_{s}, \kappa_{\ell}^{j}<1$ the economy is partially locked down. Denoting essential occupations by $j=E$, we assume that $\kappa_{\ell}^{E}=1$ always, meaning that essential occupations can continue to work in the workplace even during a lockdown. Because we let the virus transmission rate $\beta_{t}$ depend on the aggregate level of social consumption and workplace hours (see equation (3)), both types of lockdown

to two sectors is straightforward, so we omit it.

${ }^{8}$ An alternative formulation would impose the constraint on the level of workplace hours directly rather than on the share $\ell_{w}^{j} \leq \kappa_{\ell}^{j}$. Both specifications capture the spirit of the stay-at-home orders, but the former is more computationally tractable. 
taper the growth of the pandemic..$^{9}$

Our specification implies that lockdowns affect the same behavioral margins as the pandemic itself. During the pandemic, individuals voluntarily substitute away from social consumption and workplace hours. During a lockdown, the government forces them to substitute along the same margins. A distinction is that the lockdown constrains the supply of social goods whereas voluntary substitution away from social goods lowers the demand for those goods.

\subsection{Equilibrium}

Given an initial condition for the pandemic $\mathcal{I}_{0}$, a lockdown policy $\left\{\kappa_{s t}, \kappa_{\ell t}^{j}\right\}_{t \geq 0}$, and a path for fiscal variables $\left\{G_{t}, \tau_{t}, \varsigma_{w t}, \varsigma_{\pi t}, T_{t}^{j}(\cdot)\right\}_{t \geq 0}$, an equilibrium in this economy is defined as paths for the pandemic state vector $\left\{\mathbf{e}_{t}\right\}_{t \geq 0}$, individual and firm decisions, distributions $\left\{\mu_{t}\right\}_{t \geq 0}$, government debt $\left\{B_{t}^{g}\right\}_{t \geq 0}$ and prices such that, at every time $t$ : (i) the state of the pandemic is determined by the law of motion (2); (ii) individuals and firms maximize their objective functions taking as given equilibrium prices, taxes, and transfers; (iii) the distribution $\mu_{t}$ satisfies aggregate consistency conditions; (iv) the government budget constraint holds; and (v) all markets clear.

There are 12 markets in our economy: liquid and illiquid asset markets, the capital market, labor markets for the five occupations, goods markets for regular and social consumption goods, and share markets for the equity of social and regular goods producers.

The liquid asset market clears when

$$
B_{t}^{h}=B_{t}^{g},
$$

where $B_{t}^{g}$ is the stock of outstanding government debt and $B_{t}^{h}=\int b d \mu_{t}$ is total individual holdings of liquid bonds. The capital market clears when capital demand by the two sectors equals capital supply by the fund

$$
K_{c t}+K_{s t}=K_{t}
$$

The markets for stocks of each sector $i$ clear when $\Theta_{i t}=1$ for $i=c, s$, where we have normalized the total number of sectoral shares to one. This implies that individuals' holdings of illiquid assets $A_{t}=\int a d \mu_{t}$ equal the value of capital plus the equity value of monopolistic producers:

$$
A_{t}=q_{t}^{k} K_{t}+q_{t}^{c}+q_{t}^{s}
$$

\footnotetext{
${ }^{9}$ Note an important difference between the workplace lockdown and the social sector lockdown. Under the former, those employed in $S$-intensive flexible occupations (e.g., an event planner or a museum curator) can work remotely and keep earning their wages. Under the latter, they cannot.
} 
The labor market for each occupation clears when

$$
N_{c, t}^{j}+N_{s, t}^{j}=\int z\left(\ell_{w t}^{j}(a, b, z, \mathfrak{a})+\phi^{j} \ell_{r t}^{j}(a, b, z, \mathfrak{a})\right) d \mu_{t}, \quad j \in \mathrm{J}
$$

Finally, the markets for regular and social goods clear when

$$
Y_{c t}=C_{c t}+I_{t}+G_{t}+\chi_{t}, \quad Y_{s t}=C_{s t}
$$

Here, $C_{c t}$ and $C_{s t}$ are total consumption expenditures in the two sectors, $I_{t}$ is gross additions to the capital stock $K_{t}, G_{t}$ is government spending, and the last term reflects transaction costs, which we interpret as financial services.

\section{Parameterization}

\subsection{Epidemiological Model}

In this section we describe our parameter choices for the epidemiological block of the model. The data that underlies these choices is rapidly evolving, and we plan to make updates as new information becomes available. Our choices reflect the state of knowledge at the time of writing in August 2020. The resulting parameter values are summarized in Table 2.

Epidemiological parameters The basic reproduction number $R_{0}(t):=\beta_{t} / \lambda_{I}$ varies over time in our model because the transmission rate $\beta_{t}$ is time-varying (see discussion below). ${ }^{10}$ We set the initial basic reproduction to $R_{0}^{\text {init }}:=R_{0}(0)=2.5$. This value is based on Liu et al. (2020), who reviewed 12 studies that estimate the basic reproduction number for COVID-19 and conclude that $R_{0}$ is likely in the range of $2-3$.

Together with the average duration of infection $T_{\mathrm{inf}}=1 / \lambda_{I}$, the initial basic reproduction rate $R_{0}^{\text {init }}$ determines the dynamics of the infection pool at the onset of the pandemic, when the behavioral response is still largely absent. From the system of equations for the dynamics of the pandemic (1) and (2), one obtains:

$$
\dot{\mathcal{I}}_{t}+\dot{\mathcal{E}}_{t}=\beta_{0} \frac{\mathcal{S}_{t}}{\mathcal{N}_{t}} \mathcal{I}_{t}-\lambda_{I} \mathcal{I}_{t} \simeq\left(\frac{R_{0}^{\mathrm{init}}-1}{T_{\mathrm{inf}}}\right) \mathcal{I}_{t}
$$

where the second approximate equality holds because in the early stages of the pandemic,

\footnotetext{
${ }^{10}$ Throughout the paper, we use $R_{0}(t)$ to refer to what the average number of secondary cases would be if the entire population were fully susceptible and remained so throughout the epidemic. This is a arguably an abuse of epidemiological terminology because epidemiologists often reserve $R_{0}$ to mean the average number of secondary cases in a fully susceptible population, i.e. our $R_{0}(0)$. Our terminology is convenient simply because $\beta_{t} / \lambda_{I}$ appears frequently in our analysis.
} 


\begin{tabular}{lcc}
\hline \hline Parameter & & Value \\
\hline Epidemiological & $T_{\text {lat }} \Rightarrow \lambda_{E}=1 / T_{\text {lat }}$ & 5.0 days \\
Average duration of $\mathcal{E}$ xposure (latent period) & $T_{\text {inf }} \Rightarrow \lambda_{I}=1 / T_{\text {inf }}$ & 4.3 days \\
Average duration of $\mathcal{I}$ nfectious & $R_{0}^{\text {init }}$ & 2.5 \\
Initial basic reproduction number & $\beta_{0}=R_{0}^{\text {init }} / T_{\text {inf }}$ & 0.58 \\
Initial transmission rate & $\mathcal{I}_{0}$ & $6.5 \times 10^{-4}$ \\
Initial condition & & \\
& & \\
Behavioral & $R_{0}^{\text {end }}$ & 2 \\
Final basic reproduction number & $t_{\text {lrn }}$ \\
Month at which learning starts & $\lambda_{\beta}$ & 4 \\
Speed of learning & $\nu_{\beta}^{s}=\nu_{\beta}^{w}$ & 0.8 \\
Behavioral elasticities & & \\
& & 0.02 \\
Clinical & $\chi$ & 10 days \\
Pr of exiting $\mathcal{I}$ nfectious and becoming $\mathcal{C}$ ritical & $T_{\text {cri }}$ & $\lambda_{C}=1 / T_{\text {cri }}$ \\
Average duration of $\mathcal{C}$ ritical state & IFR & 0.01 \\
Infection fatality rate & $\delta_{C}$ & 0.33 \\
Pr of dying when $\mathcal{C}$ ritical \& $\mathcal{C} \leq \mathcal{C}$ max & $\delta_{C}+\Delta C$ & 1 \\
Pr of dying when $\mathcal{C}$ ritical \& $\mathcal{C}>\mathcal{C}$ max & $\mathcal{C}_{\text {max }}$ & 0.00024 \\
ICU Capacity / Adult Population & $\lambda_{R}$ & 0 \\
Rate at which $\mathcal{R}$ ecovered become $\mathcal{S}$ usceptible again & $t_{\text {vac }}$ & 24 \\
Month at which vaccine arrives & & \\
\hline
\end{tabular}

Table 2: Parameterization of the epidemiological/clinical block of the model.

the entire population is susceptible $\mathcal{S}_{t} \simeq \mathcal{N}_{t}$. This equation states that the initial growth rate of infections is $\left(R_{0}^{\text {init }}-1\right) / T_{\text {inf }}$. In most countries the initial growth rate of infections in the first week was around $35 \%$, which implies $T_{\mathrm{inf}}=4.3 .{ }^{11}$ This estimate is within the 'best estimate' interval of 4-5 days reported in the compendium by Bar-On et al. (2020). The same authors report 'best estimates' for the median latent period (the time between exposure and becoming infective) between 3 and 4 days. A median of 3.5 days implies $T_{\text {lat }}=1 / \lambda_{E}=5$.

Behavioral parameters The infection transmission rate $\beta_{t}$ varies over the course of the pandemic, because individuals alter their behavior either voluntarily, or due to a lockdown. As indicated by the arguments of equation (3), we allow for three behavioral channels: changes in social consumption $\left(C_{s t}\right)$, changes in workplace hours $\left(L_{w t}\right)$ and exogenous learning about best-practice behavior during a pandemic, such as wearing face masks $(t)$. We assume the following isoelastic functional form for the function $\beta\left(C_{s t}, L_{w t}, t\right)$ :

$$
\beta_{t}=\tilde{\beta}_{t}\left(\frac{C_{s t}}{\bar{C}_{s}}\right)^{\nu_{\beta}}\left(\frac{L_{w t}}{\bar{L}_{w}}\right)^{\nu_{\beta}},
$$

\footnotetext{
${ }^{11}$ See, for example, https://www.ft.com/coronavirus-latest, which collects data on the evolution of infections across countries. The first week is defined as the week after the first 3 cases were officially detected.
} 

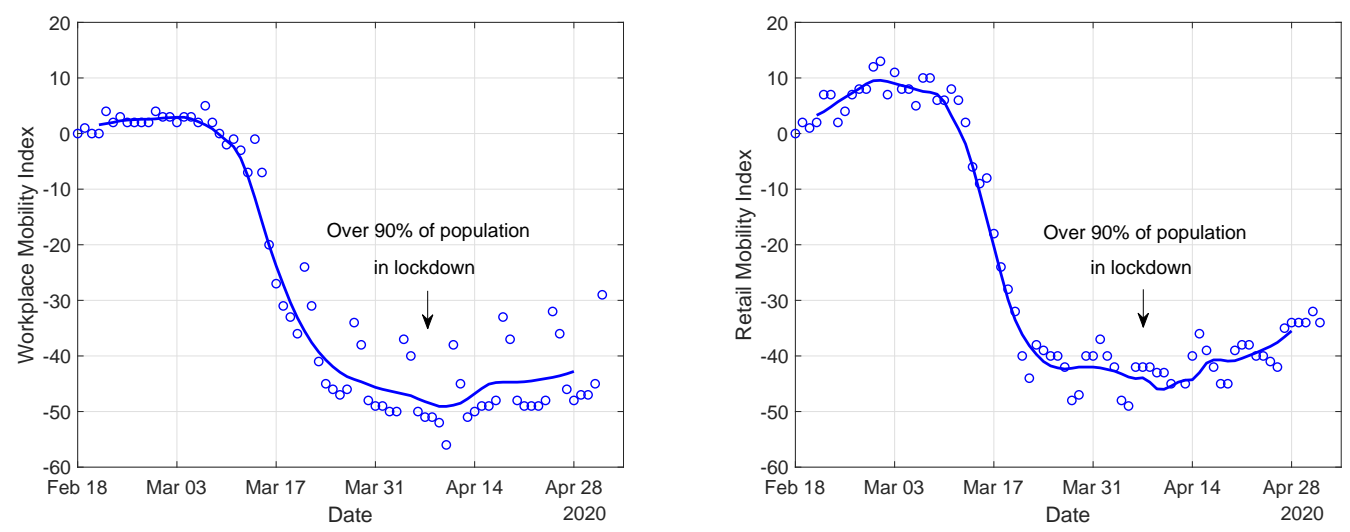

Figure 2: Percentage decline in mobility for 'workplace' (left panel) and 'retail and recreation' (right panel) in the US relative to the baseline (median value, for the corresponding day of the week, during the 5-week period Jan 3 - Feb 6, 2020). These are the empirical proxies for hours worked in the workplace and expenditures on social good in the model. The circles are the raw data, the solid fitted lines are 7-day moving averages to filter out seasonality. Source: Google COVID-19 Community Mobility Reports.

where $\tilde{\beta}_{t}$ captures the exogenous reductions in transmission rates through learning about best-practice behavior. The parameter $\nu_{\beta}$ measures the elasticity of the transmission rate to changes in social consumption and workplace hours. ${ }^{12}$

According to Ferguson et al. (2020), shelter-in-place measures can reduce contacts outside households by up to $75 \%$ under full compliance. Real-time estimates of the effective reproduction number $R_{t}=R_{0}(t) \times \mathcal{S}_{t}=\beta_{t} / \lambda_{I} \times \mathcal{S}_{t}$ for the U.S. imply reductions of $R_{t}$ of around two-thirds (with some notable variation across states) after the lockdown was put in place. ${ }^{13}$ Since lockdowns were put in place early in the pandemic when $\mathcal{S}_{t} \simeq 1$, these estimates imply a reduction in $R_{0}(t)$ by a similar amount.

Google COVID-19 Community Mobility Reports offer an indication of the magnitude of the decline in social consumption and on-site work, as they chart physical movements between different categories of places, including retail \& recreation and workplace. ${ }^{14}$ These data, summarized in Figure 2, show that over the period where most U.S. states were under a full lockdown, activity in retail and workplace declined by roughly $50 \%$ compared to mid February 2020. Under the assumption that the reduction in workplace and in retail \& recreation mobility are good proxies for the cutback in onsite work hours and expenditures

\footnotetext{
${ }^{12}$ The quadratic matching nature of the SIR model means that what matters is for transmission is average hours worked of the susceptible times average hours worked of the infectious. In our model the two are the same, which justifies the use of the average across population groups in (19). The Cobb-Douglas specification captures the idea that there is a complementarity between the reduction in workplace and retail activities in containing the spread of the virus. An alternative specification without complementarity is $\beta_{t}=\tilde{\beta}(t)\left[\left(\frac{C_{s t}}{\bar{C}_{s}}\right)^{\nu_{\beta}}+\left(\frac{L_{w t}}{\bar{L}_{w}}\right)^{\nu_{\beta}}\right]$.

13 These estimates are provided by The COVID Tracking Project and available at https://rt.live.

${ }^{14}$ See https://www.google.com/covid19/mobility.
} 
on social goods, respectively, a fall in $R_{0}(t)$ from 2.5 to 0.82 ( $-66 \%$ from 2.5$)$ implies $\nu_{\beta}=0.8$.

The exogenous component $\tilde{\beta}_{t}$ captures reductions in the transmission rate $\beta_{t}$ that arise from changes in social norms about cheap preventive measures, such as wearing masks, washing hands, etc. We specify this time path in terms of $\tilde{R}_{0}(t):=\tilde{\beta}_{t} / T_{\text {inf }}$, which is the exogenous component of the basic reproduction number (i.e. the basic reproduction number $R_{0}(t)$ in the absence of behavioral feedback from social consumption or workplace hours). To capture the typical path of learning dynamics, we assume that $\tilde{R}_{0}(t)=(1-\omega(t)) R_{0}^{\text {init }}+$ $\omega(t) R_{0}^{\text {end }}$ with $R_{0}^{\text {end }}<R_{0}^{\text {init }}$. We assume that $\omega(t)=1 /\left(1+e^{-\lambda_{\beta}\left(t-t_{\operatorname{lrn}}\right)}\right)$ follows a logistic learning curve as in Griliches (1957) and can be interpreted as the fraction of the population who have learned about best-practice behaviors. We set $R_{0}^{\text {end }}=2$ so that the exogenous component of the transmission rate $\tilde{R}_{t}$ declines by $20 \%$ from its initial value of $R_{0}^{\text {init }}=2.5$ over the course of the pandemic. ${ }^{15}$ We set $t_{\mathrm{lnn}}=4$ months and $\lambda_{\beta}=2$ which implies that most of the learning takes place within 4 months.

Clinical parameters The clinical parameters of the model are taken from Ferguson et al. (2020) (a.k.a the Imperial College Report), most of which are in line with the estimates from Zhou et al. (2020) using data from the Wuhan episode. According to this report, the average duration of the critical state $T_{\text {cri }}=1 / \lambda_{c}$ is 10 days, the death probability conditional on being critical is $33 \%$, and the overall infection fatality rate (IFR) is around $0.66 \%$, which is also the midpoint of the estimate in Bar-On et al. (2020). Because only critically ill individuals die in our model, IFR $=\chi \times 33 \%$ which requires setting $\chi$, the probability of becoming critical when exiting the $\mathcal{I}$ state, to $2 \%{ }^{16}$

We parameterize ICU capacity $\mathcal{C}_{\max }$ as the number of ICU beds relative to the initial population, which we interpret as the U.S. adult population of roughly 250 million people. According to the Harvard Global Health Institute, there are around 60,000 ICU beds available in U.S. hospitals, implying $\mathcal{C}_{\max }=0.00024 .{ }^{17}$ We assume that when the health care system is at capacity, all critically ill who exceed the number of available beds die with certainty.

Finally, we assume that a vaccine yielding full immunity starts being distributed in month $t_{\mathrm{vac}}=24$ after the initial outbreak of the virus, and the entire population is vaccinated very rapidly.

\footnotetext{
${ }^{15}$ Some empirical papers studying the efficacy of masks and other cheap preventive measures argue for even larger drops in $R_{0}$ of up to $40 \%$ (see e.g. Mitze et al., 2020). We have also experimented with such larger drops and these alternative assumptions do not affect our main results much.

${ }^{16}$ The Imperial College report sets $\chi$ to $1.5 \%$, the product of a $5 \%$ hospitalization rate and $30 \%$ probability of ending in ICU when hospitalized. Wu and McGoogan (2020) estimate $\chi$ between $3 \%$ and $5 \%$ using data for China.

${ }^{17}$ Source: https://globalpandemics.org/our-data/hospital-capacity.
} 

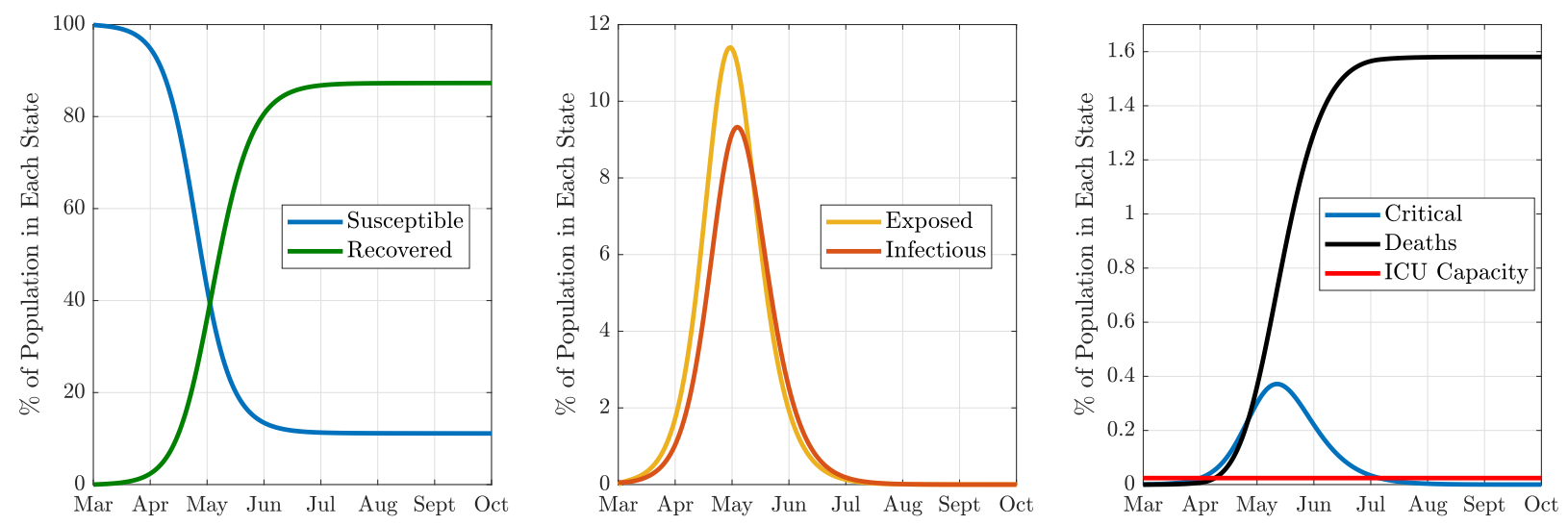

Figure 3: 'Naive' dynamics of pandemic without behavioral response (i.e., $\beta_{0}$ fixed at 0.58 ) and without lockdowns.

Benchmark pandemic dynamics We interpret $t=0$ as 1 March 2020 and set $\mathcal{I}_{0}=$ $6.5 \times 10^{-4}$ at this date. With this initial condition, our baseline simulations that include the endogenous behavioral feedback and a lockdown designed to mimic the one in the U.S., imply that there are around 100,000 deaths after 3 months, as in the data. ${ }^{18}$

For ease of comparison with other studies, Figure 3 plots the counterfactual dynamics of the pandemic in the absence of any behavioral feedback $\left(t_{\operatorname{lrn}}=\infty, \nu_{\beta}^{s}=\nu_{\beta}^{\ell}=0\right)$ and without any lockdown or other interventions, which we refer to as the naive model dynamics. The naive model dynamics predict a peak of active infections of approximately $9 \%$ of the population after less than 3 months and a final cumulative infections of approximately $87 \%$ of the population. Therefore, total infections overshoot quite dramatically the herd immunity threshold of $1-1 / R_{0}^{\text {init }}=60 \%$. Cumulative deaths are roughly $1.6 \%$ of the population, and hence almost three times as large as the number implied by the baseline IFR of $0.66 \%$, i.e. $0.66 \% \times 87 \%=0.57 \%$, because the ICU constraint binds for almost three months during the pandemic. These extremely dire clinical predictions are based on the naive version of the model that abstracts from both the behavioral response and public health interventions, both of which happened in reality and which we incorporate in our full model.

\subsection{Economic Model}

\subsubsection{Production}

Sectors The Bureau of Economic Analysis's (BEA) 2-digit 2017 NAICS industry classification contains 21 private sector industries. ${ }^{19}$ We allocate each of these industries to either the regular $(c)$ or social $(s)$ sectors based on the degree of social interaction, either with

\footnotetext{
${ }^{18}$ Source: https://covidtracking.com/data/us-daily.

${ }^{19}$ Source: Table 'Components of Value Added by Industry,' https://www.bea.gov.
} 


\begin{tabular}{llll}
\hline \hline NAICS code & Sector $C$ (value added share: 0.74) & NAICS code & Sector $S$ (value added share: 0.26) \\
\hline 11 & Agriculture, forestry, fishing, and hunting & $44-45$ & Retail trade \\
21 & Mining & $481-482-483$ & Air, rail, and water transportation \\
22 & Utilities & $485-487-488$ & Transit and scenic transportation \\
23 & Construction & 61 & Educational services \\
$31-32-33$ & Manufacturing & 62 & Health care and social assistance services \\
42 & Wholesale trade & $531-532-533$ & Real estate, rental and leasing services \\
$484-486$ & Truck and pipeline transportation & 71 & Arts, entertainment, and recreation services \\
$491-492$ & Postal transportation & 72 & Accommodation and food services \\
493 & Warehousing and storage & 81 & Other services (excluding P.A.) \\
51 & Information & & \\
52 & Finance and insurance & & \\
- & Housing services & & \\
$54-55$ & Professional, technical, and scientific services & & \\
56 & Management and administrative services & & \\
\hline
\end{tabular}

Table 3: Classification of 2-digit NAICS industries into $c$ and $s$ sectors.

other customers or with workers, required to consume them. According to our classification, reported in Table 3, the total value added share of the $c$ sector is 0.74 and the value added of the $s$ sector is 0.26 . Using industry-level labor shares, we also compute the implied labor shares in the two sectors. We find that the social goods sector is much more labor intensive than the regular goods sector, with a $54 \%$ larger labor share. ${ }^{20}$

Occupations We assume that individuals work in one of $J=5$ occupations. One of these occupations, labeled $E$, consists of essential workers who are not affected by the lockdown. The four non-essential occupations are differentiated in terms of their flexibility ( $F$ for more flexible, $R$ for more rigid) and their sectoral intensity ( $C$ for more intensive in production of regular goods, $S$ for more intensive in production of social goods). So for example, occupation $C F$ contains workers who can work from home with relatively little loss in productivity, and produce goods or services that entail relatively little social interaction. ${ }^{21}$

To calibrate occupation-level parameters, we categorize each of the 430 5-digit 2010 SOC occupation codes as either flexible or rigid, based on the analysis of O*NET data in Dingel and Neiman (2020a), and our own analysis of American Time Use Survey (ATUS). In Appendix B.1, we show that the employment weighted correlation between these two measures is 0.8 . We use the $\mathrm{O}^{*} \mathrm{NET}$ based classifications for our calculations. We categorize

\footnotetext{
${ }^{20}$ Some industries map cleanly into the regular or social goods sector. For example, food services (e.g. restaurants), other services (e.g. hairdressers), and entertainment (e.g. movie theaters) fit naturally in the $s$ sector, whereas mining, manufacturing, and finance fit naturally in the $c$ sector. Within more ambiguous industries, we separated out 4-digit sub-industries into different sectors. For example, in the transportation industry, we included rail, air and transit transportation in the $s$ sector, but we included postal, pipeline and truck transportation in the $c$ sector. Similarly, in the real estate, rental and leasing sector, we included real estate (e.g. services from housing) in the $c$ sector, but we included other rental services (e.g. services of real-estate and car-rental agents) in the $s$ sector.

${ }^{21}$ Recall that Table 1 illustrates several examples of occupations in each of the five groups.
} 


\begin{tabular}{cccccccc}
\hline $\begin{array}{c}\text { Occupation } \\
\text { Type }\end{array}$ & $\phi^{j}$ & $\begin{array}{c}\text { Share of } \\
\text { Lab Inc C }\end{array}$ & $\begin{array}{c}\text { Share of } \\
\text { Lab Inc S }\end{array}$ & $\xi_{c}^{j}$ & $\xi_{s}^{j}$ & $\begin{array}{c}\text { Average } \\
\text { Earnings }\end{array}$ & $\begin{array}{c}\text { Employment } \\
\text { Share }\end{array}$ \\
\hline$E$ & 0.01 & 0.211 & 0.353 & 0.191 & 0.356 & 44,745 & 0.308 \\
$C F$ & 0.99 & 0.535 & 0.118 & 0.575 & 0.141 & 79,422 & 0.211 \\
$C R$ & 0.10 & 0.191 & 0.041 & 0.181 & 0.043 & 44,813 & 0.133 \\
$S F$ & 0.99 & 0.028 & 0.193 & 0.025 & 0.193 & 50,619 & 0.104 \\
$S R$ & 0.10 & 0.035 & 0.295 & 0.028 & 0.267 & 32,000 & 0.244 \\
\hline
\end{tabular}

Table 4: The five occupation groups in the model: Essential $(E)$, C-intensive Flexible $(C F)$, C-intensive Rigid $(C R)$, S-intensive Flexible $(S F)$, S-intensive Rigid $(S R)$. Sectoral labor shares, employment and earnings. Earnings are in 2017 dollars.

each occupation as either $C$-intensive or $S$-intensive based on their relative labor shares in the industries in each sector, as reported in Table 3. We define essential workers as those in both occupations with low flexibility and industries that are classified by the Department of Homeland Security as "critical infrastructure workers". Appendix B.1 contains a detailed description of this procedure.

Table 4 reports the average earnings and employment shares of each of the five occupations and the share of total labor income in the $C$ and $S$ sectors going to each occupation. Average annual earnings are highest for the $C$-intensive flexible occupations $(\$ 79,000)$ and lowest for the $S$-intensive rigid occupations $(\$ 32,000)$.

Technology We set the flexibility indexes $\left\{\phi^{j}\right\}$ for the essential and flexible occupations very close to 0 and 1 , respectively to respect the nature of these definitions. For the rigid occupations we set the index to 0.10 which allows for the small amount of remote work that we observe in the data for these groups. The ten share parameters $\left\{\xi_{c}^{j}, \xi_{s}^{j}\right\}$ in the intermediate goods production function are set to match the occupational labor income shares in the $c$ and $s$ sectors reported in Table 4 . The capital share parameters $\alpha_{c}$ and $\alpha_{s}$ are set to replicate an aggregate labor share of 0.60 , with the ratio of labor shares in the two sectors calibrated to 1.54, as estimated from BEA data and described above.

The elasticity of substitution across occupations is set to 1.25 in both sectors. With this value, the drop in labor earnings of the five occupations in our baseline experiment matches closely the drops observed in US data between March and May (source: Monthly CPS). We set the within-sector elasticity of substitution across intermediate goods producers in both sectors to $10\left(\epsilon_{c}=\epsilon_{s}=10\right)$.

The functional form for the capital adjustment cost is $\phi(\iota)=\frac{1}{\delta_{k} \vartheta}\left(\iota-\delta_{k}\right)^{2}$. We set $\vartheta$, which measures the elasticity of the investment rate to (small changes in) the shadow price of capital, to 4 . This value yields a drop in investments around 10\% in Q2:2020, in line with the aggregate U.S. data. ${ }^{22}$ The annual depreciation rate on capital $\delta_{k}$ is set to $10 \%$.

\footnotetext{
${ }^{22}$ Series: Private Non-residential Fixed Investment (PNFI) in FRED, https://fred.stlouisfed.org/.
} 


\begin{tabular}{lccccc}
\hline \hline & $E$ & $C F$ & $C R$ & $S F$ & $S R$ \\
\hline Median net liquid wealth (\$) & 1,312 & 18,375 & 1,013 & 8,916 & 875 \\
Share of Hand-to-Mouth & 0.453 & 0.272 & 0.465 & 0.327 & 0.499 \\
Share of Poor HtM & 0.186 & 0.069 & 0.195 & 0.097 & 0.255 \\
Share of Wealthy HtM & 0.267 & 0.203 & 0.270 & 0.230 & 0.244 \\
\hline Liquid rate wedge (\%) & 0 & 0.2 & -0.7 & 1.2 & -1.0 \\
\hline
\end{tabular}

Table 5: Median net liquid wealth holdings, and hand-to-mouth (HtM) shares by occupational group. Source SIPP, Waves 1-4 2014.

\subsubsection{Households}

Asset returns and transaction costs We choose the following function form for household transaction costs:

$$
\chi(d, a)=\chi_{1}\left|\frac{d}{a}\right|^{\chi_{2}} a
$$

The restriction $\left(\chi_{1}>0, \chi_{2}>1\right)$ ensures the function is increasing and convex in $d$. Under these assumptions, deposit rates are finite, $\left|d_{t}\right|<\infty$, and hence individual's holdings of assets never jump. ${ }^{23}$

We choose the two parameters of the transaction cost function $\left(\chi_{1}, \chi_{2}\right)$ to generate a total share of hand-to-mouth households of $40 \%$, of which two-thirds are wealthy hand-to-mouth households as in the 2016 Survey of Consumer Finances (SCF 2016). In both model and data, we define a household as hand-to-mouth if its holdings of liquid wealth are less than $\$ 1,000$ and as wealthy hand-to-mouth if, in addition, its holdings of illiquid wealth are more than $\$ 1,000 .^{24}$

We choose the real interest rate on liquid assets $r^{b}$ to match an overall median holdings of liquid wealth of $\$ 3,500$ (SCF 2016). The annualized calibrated value of $r^{b}$ is $2.8 \%$.

In our model, the main determinant of whether households are able to weather income shocks is their holdings of liquid wealth. It is thus important that the model is consistent with heterogeneity across occupations in liquid wealth. Table 5 shows median net liquid wealth for each of the five occupation groups, together with the share of total, poor and wealthy hand-to-mouth households in each group. Since the publicly available SCF micro-data does not contain detailed occupation information, these statistics are based on data from the

\footnotetext{
${ }^{23}$ Scaling by illiquid assets $a$ delivers the desirable property that marginal costs $\chi_{d}(d, a)$ are homogeneous of degree zero in $(d, a)$ so that the marginal cost of transacting depends on the fraction of illiquid assets transacted, rather than the raw size of the transaction. Because the transaction cost is infinite at $a=0$, for computational purposes we replace the term $a$ with $\max \{a, \underline{a}\}$, where the threshold $\underline{a}>0$ is a small value (around \$500) that guarantees costs remain finite even for individuals with $a=0$.

${ }^{24}$ Our definitions of liquid and illiquid net worth are the same as in Kaplan et al. (2014) and Kaplan et al. (2018). Net liquid wealth is defined as banks deposits plus directly held mutual funds, stocks and bonds times an adjustment of $5 \%$ of liquid assets for cash holdings (not recorded in the SCF) net of credit card debt. Net illiquid wealth is the sum of housing net worth and wealth in retirement accounts, plus other small items like CDs and life insurance.
} 
Survey of Income and Program Participation (SIPP Waves 1-4, 2014). ${ }^{25}$ Table 5 reveals that workers in rigid and essential occupations are significantly more financially vulnerable than those in flexible occupations. To match this heterogeneity in median liquid wealth, we introduce an occupation-specific wedge in the liquid rate which should be interpreted as a reduced-form catch-all for heterogeneity in financial sophistication, intermediation costs, informational frictions, structural barriers to financial markets and behavioral phenomena. We normalize the wedge for essential workers to zero.

The aggregate quarterly MPC in the model is 0.14. As extensively discussed in Kaplan and Violante (2020), it is the combination of uninsurable risk and two-asset structure that enables the model to simultaneously generate a large amount of aggregate net worth and a high aggregate MPC (roughly 10 times the MPC in a representative agent model) without preference heterogeneity.

Preferences We choose the discount rate $\rho$ to replicate a ratio of total illiquid net worth to annual GDP of 4.5 (SCF 2016) which, in turn, implies a steady-state annualized value of $r^{a}=0.05$.

We assume the following functional form for period utility $U\left(c, v_{s}(\dot{\mathcal{D}}) s, h\right)-V\left(v_{\ell}(\dot{\mathcal{D}}) \ell_{w}, \ell_{r}, \ell_{h}\right)$ in (5)

$$
U\left(c, v_{s}(\dot{\mathcal{D}}) s, h\right)=\frac{c^{1-\gamma}}{1-\gamma}+\varphi_{s} \frac{\tilde{s}^{1-\gamma}}{1-\gamma}, \quad \tilde{s}=\left(v_{s}(\dot{\mathcal{D}}) s^{\frac{\theta-1}{\theta}}+h^{\frac{\theta-1}{\theta}}\right)^{\frac{\theta}{\theta-1}}
$$

with $\gamma, \varphi_{s}>0$ and $\theta>1$ and

$$
V\left(v_{\ell}(\dot{\mathcal{D}}) \ell_{w}, \ell_{r}, \ell_{h}\right)=\varphi_{\ell} \frac{\tilde{\ell}^{1+\zeta}}{1+\zeta}+\varphi_{h} h, \quad \tilde{\ell}=\left(v_{\ell}(\dot{\mathcal{D}}) \ell_{w}^{\frac{1+\eta}{\eta}}+\ell_{r}^{\frac{1+\eta}{\eta}}\right)^{\frac{\eta}{1+\eta}}
$$

with $\zeta, \varphi_{\ell}, \varphi_{h}>0$ and $\eta \geq 0$.

We set $\gamma=1 .{ }^{26}$ We choose $\varphi_{s}$ so that the output share in the $s$ sector is $26 \%$. Estimates of the elasticity of substitution between market consumption and home, $\theta$, using micro data typically obtain values just below 2 (e.g., Aguiar and Hurst, 2007a). We set $\theta=2$ because $s$ goods are arguably more substitutable with home production than the whole market consumption bundle. The shifters $v_{s}$ and $v_{\ell}$ are normalized to one in steady-state.

\footnotetext{
${ }^{25}$ We can construct measures of liquid and illiquid wealth in the SIPP that are very close to those in the SCF. We define hand-to-mouth households as described above for the SCF. The total share of HtM households in SIPP is $40 \%$, and the fraction of wealthy HtM among these is around $60 \%$, consistent with the SCF. Median household liquid wealth in SIPP is somewhat smaller than in the SCF, so we rescale all SIPP observations by a constant factor to match the SCF median. See Appendix B.2 for details.

${ }^{26}$ Note that $1 / \gamma$ denotes both the intertemporal elasticity of substitution for both consumption goods and the static elasticity of substitution between $c$ and the composite $(s, h)$ bundle. To assess whether the latter elasticity is in the right ballpark, we construct quantities and price indexes for $c$ and $s$ goods for the US economy from 1947 to 2019. Time-series regressions of log relative quantities on log relative prices also yield an elasticity around one. See Appendix B.3 for details.
} 
We set the Frisch elasticity of labor supply $1 / \zeta$ to 1 . The parameter $\eta$ governs the degree of substitution between supplying labor remotely and in the workplace. When $\eta \rightarrow \infty$, workplace and remote hours are perfect substitutes in preferences. We normalize the time endowment to one and set $\left(\varphi_{\ell}, \varphi_{h}, \eta\right)$ to match three moments about hours worked: (i) total market hours $\ell_{w}+\ell_{r}$ equal to 0.34 ; (ii) remote market hours as a share of total market hours $\ell_{r} /\left(\ell_{w}+\ell_{r}\right)$ equal to 0.10 ; (iii) home production hours as a share of total hours worked $\ell_{h} /\left(\ell_{w}+\ell_{r}+\ell_{h}\right)$ equal to 0.18. The first two moments are taken from Aguiar and Hurst (2007b, Table 2). The third moment is computed from the most recent wave of ATUS for 2019. ${ }^{27}$

Finally we set the exogenous level of consumption of the two goods $(\underline{c}, \underline{s})$ for the critically ill to 0.14 , which is roughly $20 \%$ of average consumption expenditures.

Optimal labor supply Lemma 1 in Appendix A characterizes optimal decisions for the three types of labor supply and three types of consumption goods. With our specification for the disutility of labor in (22), the optimal share of workplace hours in total market hours in the absence of a lockdown is given by

$$
s_{w}:=\frac{\ell_{w}}{\ell_{r}+\ell_{w}}=\frac{v_{\ell}(\dot{\mathcal{D}})^{-\eta}}{v_{\ell}(\dot{\mathcal{D}})^{-\eta}+\phi^{\eta}},
$$

where $\phi$ is the individual's occupation flexibility index and $v_{\ell}(\dot{\mathcal{D}})$ is the additional disutility of workplace hours due to the virus.

The share of workplace hours is decreasing in flexibility $\phi$ and equals one if $\phi=0$, so that individuals in fully rigid occupations only work onsite. Whenever $\phi>0$, this share is decreasing in disutility $v_{\ell}(\dot{\mathcal{D}})$, so individuals substitute toward remote work when deaths from the virus increase. The size of both of these margins of substitution is governed by the elasticity parameter $\eta$. It follows from (23) that the labor lockdown constraint (13) binds whenever $\kappa_{\ell}^{j}$ is less than this unconstrained share of workplace hours. Symmetric expressions hold for demands for social and home-produced goods.

Feedback from virus to economic activity We parameterize the disutility functions that govern feedback from the virus to the economic decisions using the functional forms,

$$
v_{s}(\dot{\mathcal{D}})=\exp \left(-\nu_{s}^{0} \dot{\mathcal{D}}^{\nu_{s}^{1}}\right), \quad v_{\ell}(\dot{\mathcal{D}})=\exp \left(\nu_{\ell}^{0} \dot{\mathcal{D}}^{\nu_{\ell}^{1}}\right)
$$

One advantage of these functional forms is that the disutility of workplace hours connects directly to calculations of the value of a statistical life (VSL). Re-arranging the static

${ }^{27}$ Bick and Blandin (2020) estimate similar numbers for the pre-lockdown period. 
optimality condition for labor supply we obtain the relationship

$$
\log w_{i t}=\gamma_{\ell}^{0}\left(\nu_{\ell}^{0} \dot{\mathcal{D}}_{t}^{\nu_{\ell}^{1}}\right)+\gamma_{\ell}^{1} \mathbf{X}_{i t}
$$

where $\beta^{0}=\frac{\eta(1+\zeta)}{1+\eta}$ and $\mathbf{X}_{i t}$ is a vector of individual correlates, that includes hours worked and consumption. The relationship between the hourly wage and death rate in equation (25) can be interpreted as a compensating differential for fatality risk, and is the foundation for most empirical estimates of VSL (see Kniesner and Viscusi, 2019, for a survey).

The specification in (24) allows for a nonlinear effect of fatality risk on compensating wage differentials. This nonlinearity is important in our context because death rates at the peak of the pandemic, when the ICU constraint binds, are one to two orders of magnitudes larger than the average fatality risk in a typical occupation. ${ }^{28}$ When $\nu_{\ell}^{1}<1$, the wage premium demanded in exchange for additional risk increases less than linearly with the level of death risk. This property, which implies that the VSL is decreasing in the level of fatality risk, is consistent with empirical evidence from high-risk occupations. ${ }^{29}$

We set the disutility parameters for workplace hours to $\nu_{\ell}^{0}=8.0$ and $\nu_{\ell}^{1}=0.6$ to match a VSL of around $\$ 10 \mathrm{M}$ for quarterly death rates of the order of $1 / 10,000$ and a VSL of around $\$ 4 \mathrm{M}$ for quarterly death rates of the order of $1 / 1,000$, based on the estimates in Lavetti (2020). Appendix B.4 contains further details of this calculation.

We set the curvature parameter for the disutility of social consumption to be the same as the curvature for workplace hours, $\nu_{s}^{1}=\nu_{\ell}^{1}=0.6$. We choose $\nu_{s}^{0}=16$ to obtain the same percentage declines in workplace hours and social consumption from the behavioral feedbacks during the pandemic.

Wage dynamics The stochastic component of individual productivities $z_{i j t}$ for an individual $i$ in occupation $j$ follows a jump-drift process in logs. Jumps arrive at a Poisson rate $\lambda_{z j}$. Conditional on a jump, a new log-productivity state $z_{i j t}^{\prime}$ is drawn from a Normal distribution with mean zero and variance $\sigma_{z j}^{2}, z_{i j t}^{\prime} \sim \mathcal{N}\left(0, \sigma_{z j}^{2}\right)$. Between jumps, the process drifts toward zero at rate $\beta_{z j}$. Formally, the process for $z_{j, i t}$ is

$$
d z_{i j t}=-\beta_{z j} z_{i j t} d t+d \Lambda_{j t}
$$

We estimate the parameters $\left\{\lambda_{z j}, \sigma_{z j}, \beta_{z j}\right\}$ using data on household wages from the PSID

\footnotetext{
${ }^{28}$ In 2020:Q1 there were around 100,000 COVID-19 related deaths in the US. This corresponds to an average fatality risk of $1 / 2,500$, compared to an average quarterly fatality risk in typical VSL calculations of $1 / 100,000$.

${ }^{29}$ Greenstone et al. (2014) emphasize non-linearities in the context of risky military occupations such as infantry, and Lavetti (2020) estimates non-linearities in the context of Alaskan fisheries, which have the largest death rate across all US civilian occupations (around 1/1,000 quarterly).
} 


\begin{tabular}{lccccc}
\hline \hline Moments & Essential & C int-Flex & C int-Rigid & S int-Flex & S int-Rigid \\
\hline Variance (lag 0) & 0.229 & 0.322 & 0.235 & 0.314 & 0.311 \\
Variance (lag 2) & 0.115 & 0.126 & 0.124 & 0.141 & 0.130 \\
Kurtosis (lag 2) & 9.87 & 8.85 & 7.77 & 8.61 & 8.74 \\
Total observations & 10,2507 & 83,473 & 30,002 & 14,994 & 40,712 \\
\hline Parameters & Essential & C int-Flex & C int-Rigid & S int-Flex & S int-Rigid \\
\hline$\lambda_{z j}$ & 0.0346 & 0.0365 & 0.0649 & 0.0346 & 0.0425 \\
$\sigma_{z j}$ & 0.736 & 0.790 & 0.627 & 0.814 & 0.764 \\
$\beta_{z j}$ & 0.0348 & 0.0315 & 0.0481 & 0.0390 & 0.0338 \\
\hline Years btw shocks & 7.23 & 6.85 & 3.85 & 7.22 & 5.89 \\
Half life of shocks & 19.9 & 22.0 & 14.4 & 17.8 & 20.5 \\
\hline
\end{tabular}

Table 6: Top table. Panel-data moments estimated on PSID biannual data 1997-2017. Dingel and Neiman (2020b) occupation classification. Bottom table: Parameter estimates via minimum distance. The parameters are expressed at quarterly frequency, the model period.

(1997-2017)..$^{30}$ We classify households in the PSID into the five occupation groups based on the occupation of the main earner in the household. For each occupation, we compute the following moments: (i) variance of log earnings, (ii) variance of 2-year log change in earnings and (iii) kurtosis of 2-year log-change in earnings. These moments are sufficient for identification (see Kaplan et al. (2018)). We estimate the parameters by minimum distance.

The empirical moments and parameter estimates for each occupation group are reported in Table 6.

\subsubsection{Government}

The government supplies all the liquid assets in the economy in the form of risk-free government debt. Given our calibration of household liquid assets, steady-state government debt $B^{g}$ is 58 percent of annual GDP.

We set the proportional labor income tax rate to $\tau=0.25$ and assume that in steady-state the transfer function $T(\cdot)$ is lump-sum and equal to 5 percent of output, which is equivalent to around $\$ 7,000$ per household per year. In steady-state, 23 percent of households receive a net transfer from the government. Expenditures are determined residually from the government budget constraint.

\footnotetext{
${ }^{30}$ We define household wages as household labor income divided by household hours worked. Our definition of labor income includes wages, commissions, overtime, and bonuses. We restrict our sample to householdyear observations with at least 520 hours worked and with an hourly wage above the federal minimum wage for that year.
} 


\begin{tabular}{lllll}
\hline \hline Parameter & & Value & Moment to Match & Value \\
\hline Technology & $Z_{c}=Z_{s}$ & 1 & Normalization & - \\
Sectoral TFP & $\alpha_{c}$ & 0.59 & Labor share in $C$ sector (BEA) & 0.53 \\
Labor share in $C$ sector & $\alpha_{s}$ & 0.90 & Labor share in $S$ sector (BEA) & 0.81 \\
Labor share in $S$ sector & $\sigma_{c}$ & 1.25 & Earnings drop across occup. in Q2 (CPS) & - \\
Elast. of subst. across occup. & $\epsilon_{c}=\epsilon_{s}$ & 10 & Profit share & 0.10 \\
Elast. of subst. for intermediates & $\delta_{k}$ & 0.10 & External & - \\
Depreciation rate & $\vartheta$ & 4 & Investment drop in Q2 (BEA) & $10 \%$ \\
Elast. of inv. to price of $K$ & & & & \\
& & & & \\
Transaction costs & $\chi_{1}$ & 0.32 & Total Share of Hand-to-Mouth (SCF) & 0.40 \\
Scale of transaction cost & $\chi_{2}$ & 1.27 & Share of Wealthy Hand-to-Mouth (SCF) & 0.26 \\
Convexity of transaction cost & & & & \\
& & & & \\
Preferences & $\rho$ & 0.025 & Illiquid wealth-income ratio (SCF) & 4 \\
Discount rate (annualized) & $1 / \gamma$ & 1 & External & - \\
IES & $\varphi_{s}$ & 1.31 & Share of value added in $S$ sector (BEA) & 0.26 \\
Weight on $S$ good & $\theta$ & 2 & External & - \\
Elasticity of substitution $(s, h)$ & $v_{\ell}=v_{s}$ & 1 & Normalization & - \\
Preference shifters & $1 / \zeta$ & 1 & External & - \\
Frisch elasticity & $\eta$ & 83.0 & Hours worked remotely (ATUS) & 0.10 \\
Elasticity of substitution $\left(\ell_{w}, \ell_{r}\right)$ & $\varphi_{\ell}$ & 9.94 & Hours worked in the market (ATUS) & 0.34 \\
Weight on remote market work & $\varphi_{\ell}$ & 3.56 & Hours worked at home (ATUS) & 0.18 \\
Weight on home work & $\varphi_{h}$ & 0.14 & External & - \\
Consumption of the critically ill & $\underline{c}, \underline{s}$ & & & \\
Government & & & & \\
Labor income tax & $\tau$ & 0.25 & Tax revenues & $0.15 \cdot G D P$ \\
Lump-sum transfer & $T$ & 0.05 & Transfers to households & \\
Government debt (liquid wealth) & $B^{g}$ & 0.58 & Liquid wealth held by hh (Flow of Funds) & $0.58 \cdot G D P$ \\
& & & & \\
\hline
\end{tabular}

Table 7: Summary of some of the parameter values and targeted moments for technology, transaction costs, preferences, and government. Remaining ones are reported in Tables 3-6. Quarterly GDP is normalized to 1 in the model.

\section{Numerical Experiments}

We organize our experiments around three scenarios. In Section 4.1, we consider a Swedenlike 'laissez-faire' scenario without government intervention. We use this scenario to develop a baseline counterfactual in which behavioral feedback is the only force limiting the spread of the virus. In Section 4.2, we consider a US-like scenario that includes the type and duration of lockdown that was observed in the United States, but without any economic stimulus package. We use this scenario to compare the trade-offs between economic and health costs under counterfactual lockdowns of different lengths and intensities. In Section 4.3, we consider a scenario that includes the complex economic stimulus program enacted by the US government, in addition to the lockdown. We use this scenario to analyze the effect of each component of the stimulus program on the trade-off, to examine the effects of counterfactual stimulus programs, and to interpret the observed time-series of consumption 
for different types of households. Finally, in Section 4.4 we consider the effects of smart containment and stimulus policies that can improve the trade-off between lives and economic welfare.

Government finances during the pandemic We assume that the monetary authority has access to a storage technology for final goods, and has accumulated a sufficient quantity of goods to provide short-term financing to the government during the pandemic. The monetary authority uses these goods to buy the additional government debt that is needed to cover the shortfall in tax revenues and finance the stimulus program. This assumption is intended to capture the role of central banks in preventing the sharp rise in governments' borrowing costs that would be required if the private sector had to absorb the additional debt. ${ }^{31}$ In the long-run, we assume that the government repays the additional debt it issues during the pandemic by smoothly raising the labor income tax rate.

Economic welfare costs We measure the economic welfare costs of the pandemic using compensating variation in liquid wealth. Consider a particular pandemic scenario that includes a specification of both lockdown and stimulus policies. Fix an individual at a particular point in the state space $(a, b, z, \mathfrak{h}, j)$ in the initial steady-state. We measure the economic cost of the pandemic for this individual as the size of the one-time liquid wealth loss that would make them indifferent between experiencing and not experiencing the pandemic. Denote the individual's steady state value function by $\overline{\mathcal{V}}$ and the value function immediately after the onset of the pandemic by $\mathcal{V}_{0}$. The economic welfare cost is given by the value of $\Omega(a, b, z, \mathfrak{h}, j)$ that solves

$$
\mathcal{V}_{0}(a, b, z, \mathfrak{h}, j)=\overline{\mathcal{V}}(a, b+\Omega, z, \mathfrak{h}, j)
$$

We report this compensating variation as a multiple of each individual's steady-state monthly disposable income (after tax earnings + asset income + transfers). This yields a distribution of economic welfare costs across households, which we use to summarize the distributional consequences of the pandemic. We measure the aggregate economic costs of a pandemic scenario as the mean or median of this distribution of income multiples.

\subsection{Laissez-Faire Scenario}

In this section we examine a scenario without any government-mandated lockdown or fiscal stimulus. This scenario forms a useful counterfactual benchmark with which to compare

\footnotetext{
${ }^{31}$ For a description of central banks' responses to the pandemic, we refer to https://research.stlouisfed. org/publications/economic-synopses/2020/04/21/central-bank-responses-to-covid-19.
} 
(a) Reproduction Number

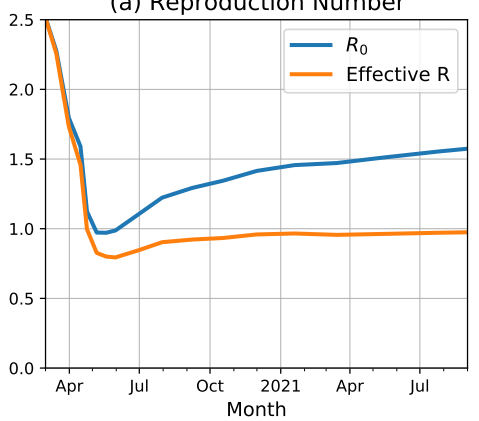

(d) Output (\%)

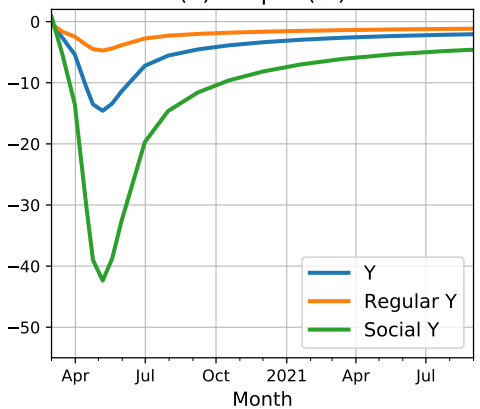

(g) Hours (\%)

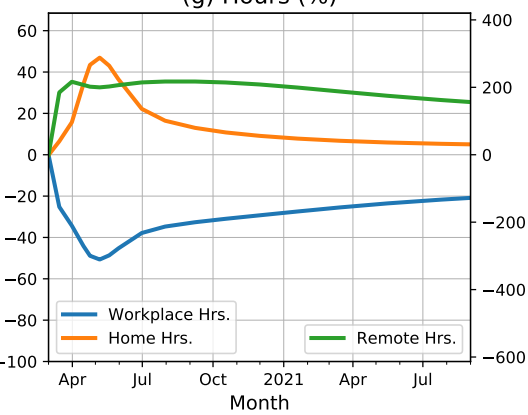

(b) Infectious (\% of Population)

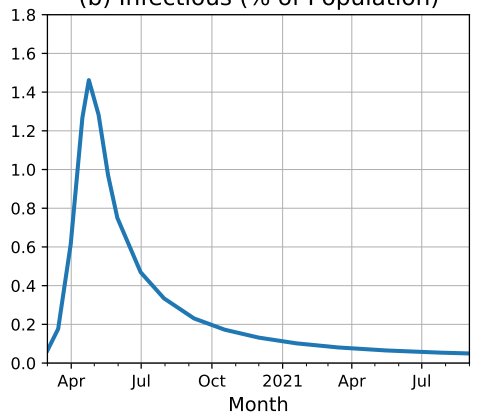

(e) Consumption (\%)

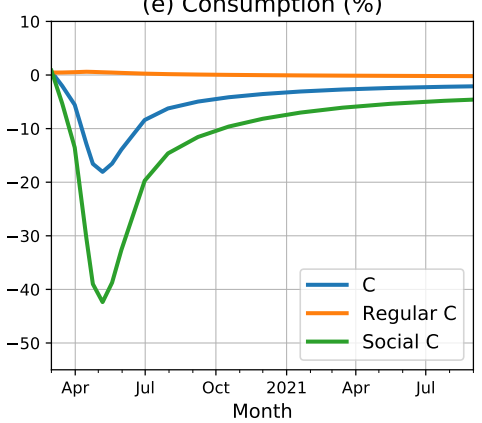

(h) Labor (\%)

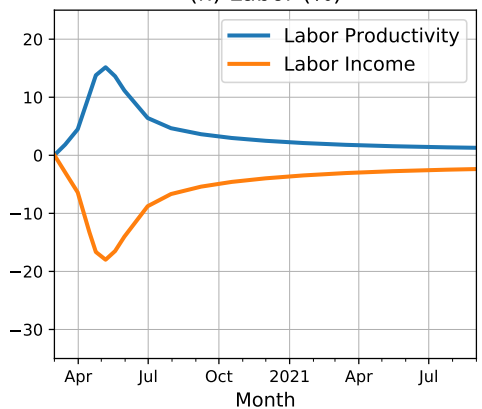

(c) Monthly Death Rate (\%)
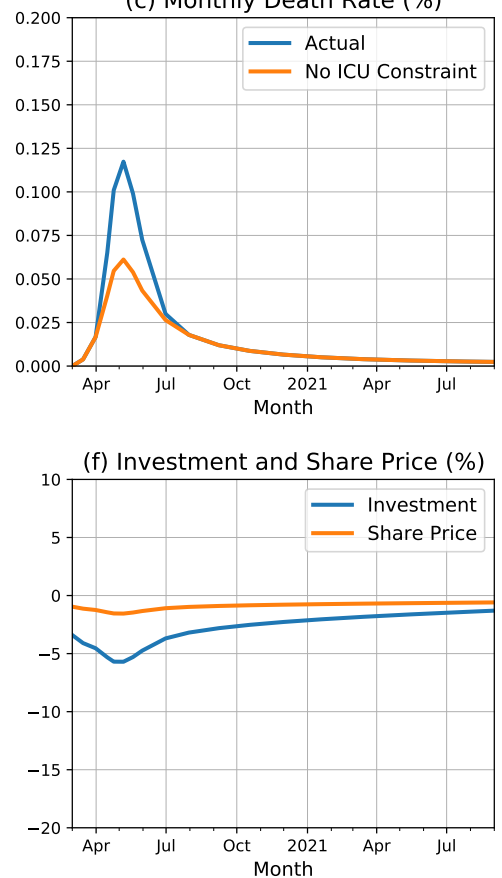

(i) $\frac{\text { Government Debt }}{\text { Quarterly GDP }}$

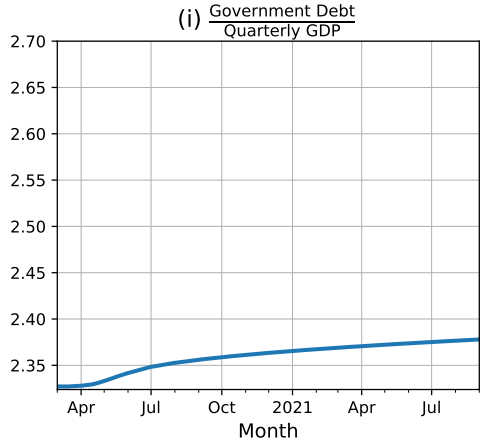

Figure 4: Laissez-faire counterfactual: dynamics of key variables

alternative policy interventions, and should not be used to compare model predictions with data.

Aggregate dynamics Figure 4 displays the aggregate dynamics of key epidemiological and economic variables. We will use versions of this figure to describe each alternative scenario that we examine. ${ }^{32}$

The top row of Figure 4 displays epidemiological variables: the basic reproduction number

\footnotetext{
${ }^{32}$ In all experiments aggregate output, consumption and investment are expressed in real terms by using their respective deflators. For example, the consumption deflator is $p_{s t}^{\operatorname{exps}_{s t}}$, where expsh ${ }_{s t}$ is the household expenditure share on goods $s$ at date $t$, since (i) the price of regular consumption is normalized to 1 at all $t$ and (i) the consumption aggregator in preferences is Cobb-Douglas. The deflator for output is analogous, but with the share of $s$ in value added instead of expenditures. The investment deflator is one at all times. Equity price and labor earnings are deflated with the consumption price index.
} 
$R_{0}(t)$, the effective reproduction number $R_{0}(t) \times \mathcal{S}_{t}$, the fraction of infectious individuals $\mathcal{I}_{t} / \mathcal{N}_{t}$, the death rate $\dot{\mathcal{D}}_{t}$ and a counterfactual death rate in the absence of constraint on ICU capacity. This latter variable helps to see the number of additional deaths that are due to the ICU constraint binding.

Without a lockdown, infections would peak at around 1.5\% of the population (around 3.75 million) in May. At this level of infections, the ICU constraint binds. Total cumulative deaths are about $0.3 \%$ of the population, but would be less than half without the ICU constraint. The high level of deaths at the peak of the pandemic triggers a strong behavioral response, which leads to a rapid decline in the basic reproduction number $R_{0}$, from 2.5 to below 1 within the first two months. The effective reproduction number also drops below 1 , and then remains roughly constant at or just below 1 for the remainder of the pandemic, in line with microfounded models of voluntary social distancing. ${ }^{33}$

The remainder of Figure 4 shows key macroeconomic aggregates. Aggregate output falls, with the majority of the drop concentrated in the social sector, due to the endogenous reduction in demand for social goods. The initial contraction is severe and short-lived, but the recovery is slow: a year later the economy is still 3\% below trend. Despite the sharp drop in social consumption expenditures, regular consumption rises only very slightly for two reasons. First, households substitute social good spending with more home production (home hours increase by 50\%, panel (g)). Second, labor income decreases sharply (panel(h)). Also aggregate investment falls (panel (f)) since the shadow value of additional capital is much reduced due to the preference-driven decline in demand and labor input. Even in the absence of fiscal stimulus, the large fall in economic activity leads to a considerable budget deficit and an increase in the debt-to-GDP ratio around 3\% (panel (i)).

Occupation dynamics Figure 5 shows the dynamics of labor income (left panel) and consumption (right panel) for the five occupation groups. There are large differences across occupations in the extent of the drop in labor income. Workers in the $S$-intensive rigid (SR) occupations experience an average fall in labor income of nearly $35 \%$, whereas those in the $C$-intensive flexible (CF) occupations experience a decline of only $6 \%$. Both labor supply and labor demand account for this large difference. Workers in the two rigid occupations supply fewer efficiency hours of labor when they substitute remote work for onsite work. The demand for workers in the two $S$-intensive occupations falls as consumers reduce their demand for social goods. While both forces are active, the labor demand effect accounts for a larger fraction of the differential falls in labor income across occupations.

In this laissez-faire scenario, labor income decreases also for essential occupations (by around $23 \%$ ) because a substantial fraction of these workers are employed in the production of social goods and services (see Table 4).

\footnotetext{
${ }^{33}$ See e.g. Farboodi et al. (2020) for a discussion of this effect.
} 
(a) Labor Income (\%)

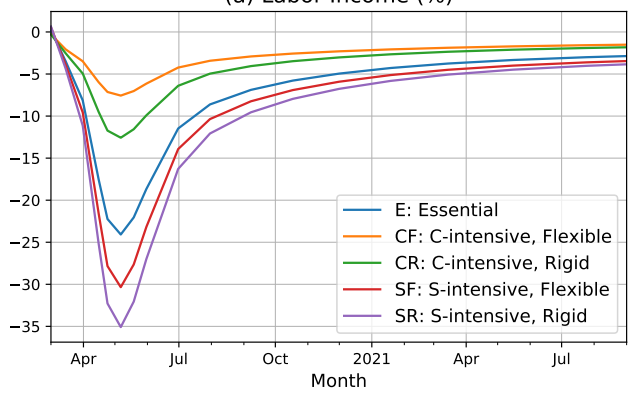

(c) Regular Consumption (\%)

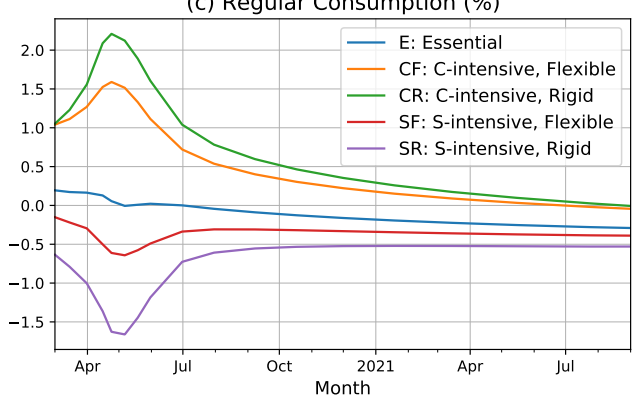

(b) Total Consumption (\%)

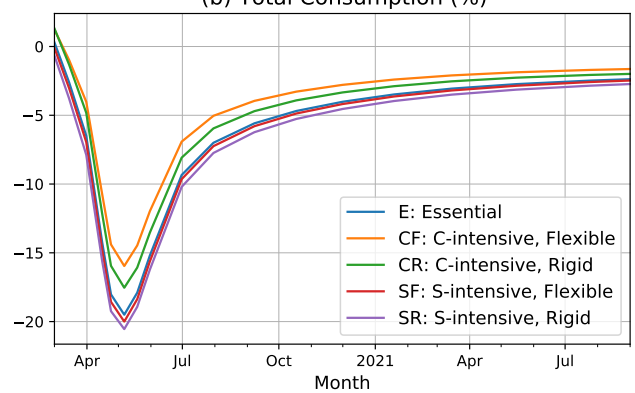

(d) Social Consumption (\%)

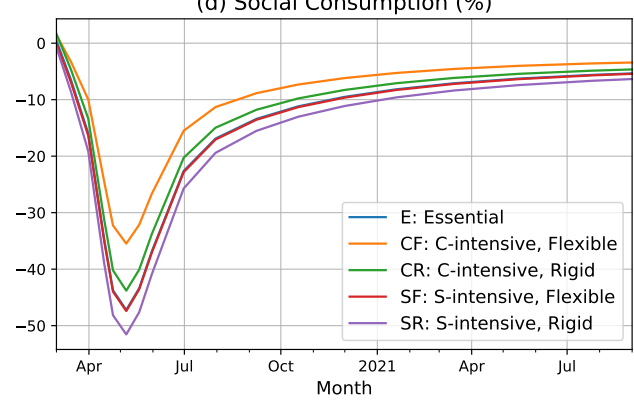

Figure 5: Laissez-faire counterfactual: distributional effects across occupations

The fall in labor income translates into a fall in spending that is ordered in the same way across occupations but is much more compressed. The decline in total consumption is driven by the collapse in $S$-sector consumption for all occupations caused by the behavioral response to the pandemic. Regular consumption rises slightly, through substitution, only for the least affected occupations.

Summarizing, in the laissez-faire scenario, both consumption and investment drop sharply. The decline in consumption is driven by the endogenous reduction in demand for the social goods. The co-movement between consumption and investment is attributable to a fall in aggregate productivity caused by workers in rigid occupations (nearly $70 \%$ of the workforce) cutting workplace hours and being less productive while working remotely. The economic consequences of the virus vary across workers in occupations with different degrees of flexibility and different exposure to the harder-hit $S$ sector.

\subsection{Lockdown Scenarios}

In this section we examine a scenario with a government-mandated lockdown that mimics those implemented in the US in the Spring of 2020, but without fiscal stimulus. As with the laissez-faire scenario, this is a counterfactual scenario that should not be used to compare model predictions with data. 
(a) Workplace Lockdown (\%)

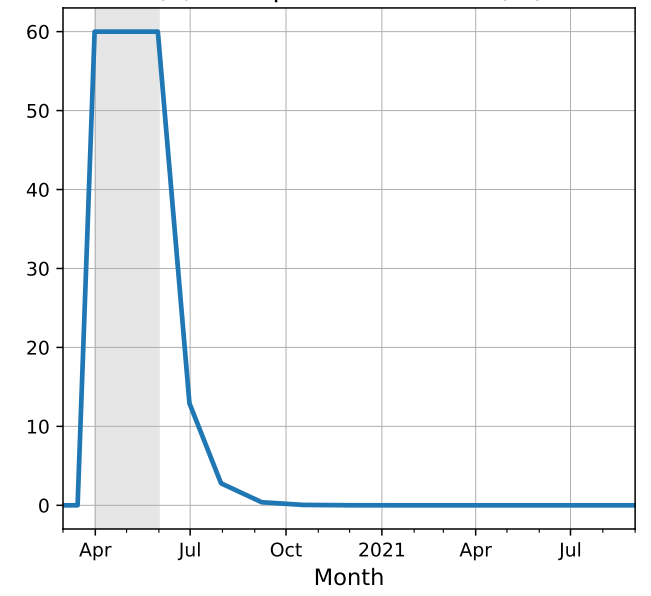

(b) Social Sector Lockdown (\%)

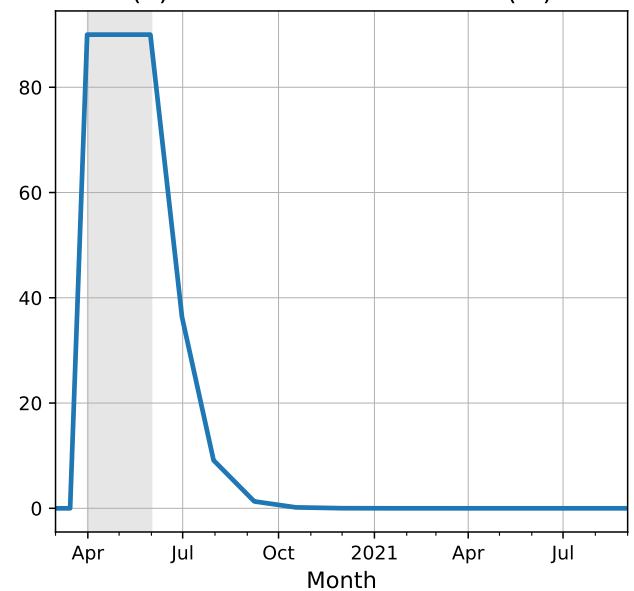

Figure 6: The two components of the baseline lockdown

Parameterization of lockdown A lockdown consists of time paths for the constraints on the share of workplace hours in total market hours for each occupation $\left\{\kappa_{\ell t}^{j}\right\}_{t \geq 0}$ (see equation (12)), and on the fraction of the capital stock in the $S$ sector that can be used for production $\left\{\kappa_{s t}\right\}_{t \geq 0}$ (see equation (13)). We assume that the workplace labor lockdown does not affect essential occupations $\kappa_{\ell t}^{E}=0$ but is common across the other four occupations.

Based on the evidence presented in Section 3.1, we calibrate the size of both lockdowns to generate a $50 \%$ reduction in workplace hours and social consumption, relative to midFebruary 2020. Recall that $t=0$ corresponds to 1 March 2020. We assume that the lockdown starts on 1 April 2020 (at $t=1$ ) and lasts until 1 June $2020(t=3)$, after which it is released quickly and is completely over by end of August $2020(t=5)$. The resulting time paths for the lockdown parameters are displayed in Figure 6, with the two-month lockdown period indicated by the grey shaded area. This lockdown scenario is designed to mimic the US lockdown in the Spring of $2020 .^{34}$

Aggregate dynamics Figure 7 displays key epidemiological and macroeconomic variables for the baseline lockdown scenario and Figure 8 contrasts them with the laissez-faire counterfactual. Three features of these dynamics stand out.

First, the initial wave of infections is dampened as a result of the lockdown, with death rates peaking at around $2.5 \%$, down from $12 \%$ in the laissez-faire scenario. This comes at

\footnotetext{
${ }^{34}$ At the time of writing in August 2020, it is unclear whether additional lockdowns will be mandated. Our baseline scenarios assume that there will be no such additional lockdowns, even in the case of a second wave of infections. It is thus crucial that our results about the future evolution of the pandemic are interpreted as conditional on this assumption about future lockdown policy. Similarly, all our conclusions in this section about the efficacy of lockdowns should be interpreted as statements about US-style lockdowns that are relatively short-lived and released quickly. We will relax these assumptions when we consider alternative lockdown policies below.
} 


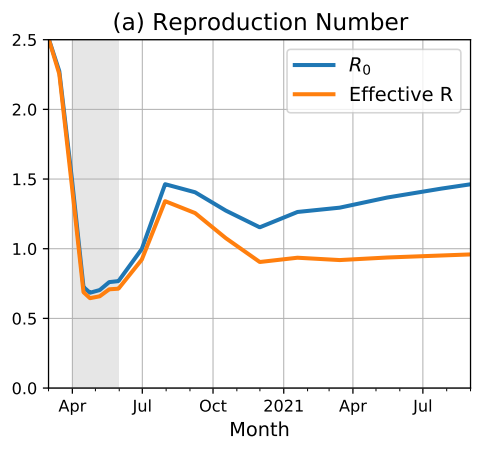

(d) Output (\%)

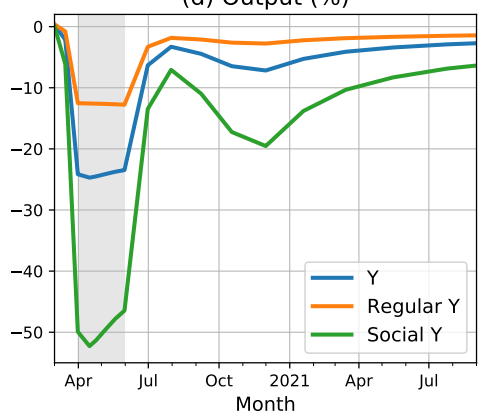

(g) Hours (\%)

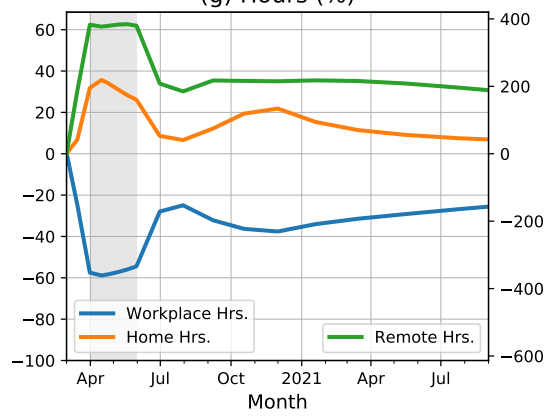

(b) Infectious (\% of Population)

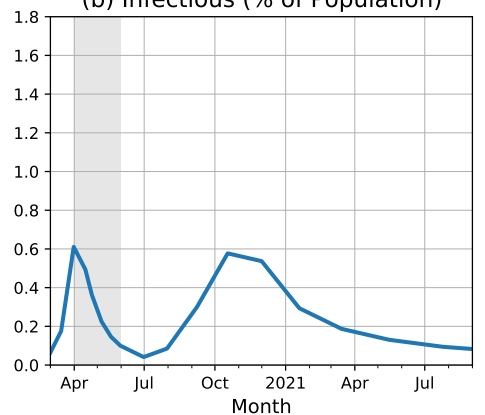

(e) Consumption (\%)

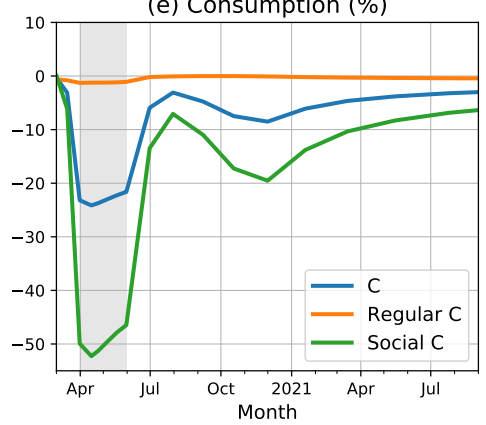

(h) Labor (\%)

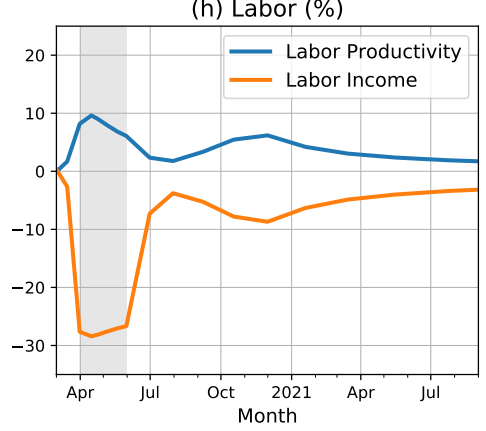

(c) Monthly Death Rate (\%)
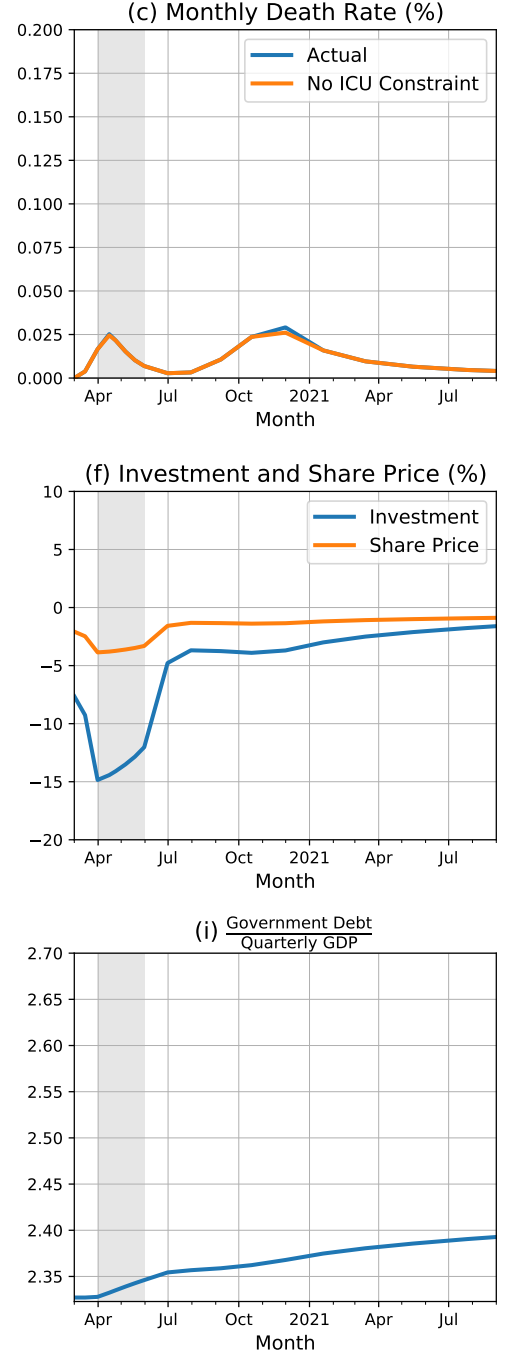

Figure 7: Counterfactual with lockdown but no fiscal policy: dynamics of key variables

the cost of a deeper and longer recession. Output falls by $17 \%$ for around 2 months under the lockdown, compared with a drop of around $14 \%$ for 1 month without the lockdown.

Second, the lockdown leads to a second wave of infections that is as large as the first wave and is longer lived. Infections start rising again at the beginning of July $(t=4)$ and reach a peak around November $(t=8)$, before slowly tapering off only in the summer of 2021. By the end of the pandemic, the lockdown reduces the cumulative number of deaths by around one-third, relative to the laissez-faire scenario. The second wave of infections brings with it a prolonged double-dip recession that is about half as large as the first. Both drops in output are concentrated in the social sector. However, in the first contraction investment also plays a major role, whereas in the second it doesn't. The reason is that the first recession is driven by the lockdown which dramatically decreases labor input and, as a result, capital productivity, whereas the second one is caused by a decline in the demand for the social 

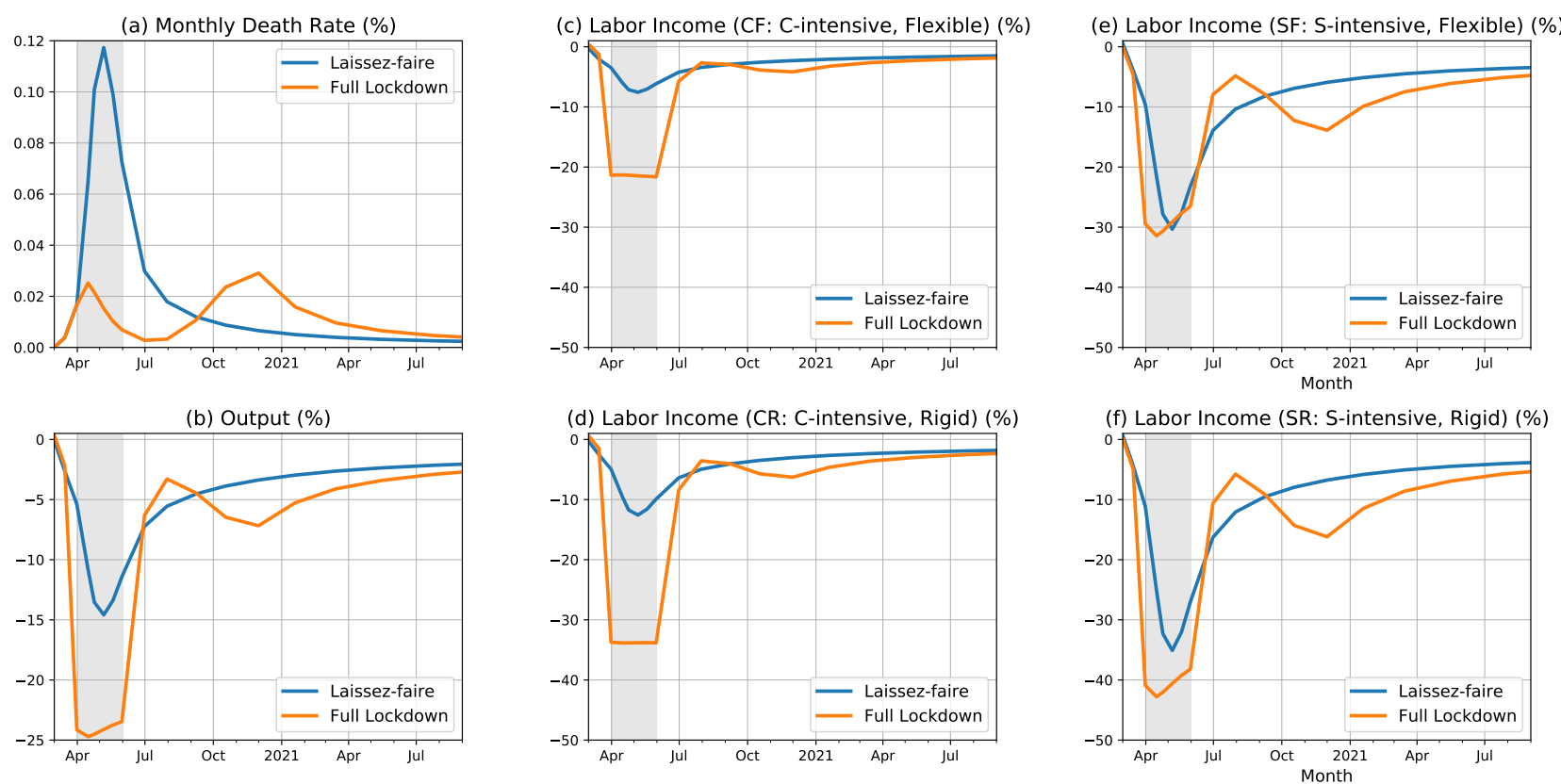

Figure 8: Comparison between laissez-faire and lockdown

sector which is not very intensive in capital.

Third, the distributional implications of the lockdown are different from those of the laissez-faire. The lockdown is extremely costly for the $C$-intensive rigid occupations whose earnings fall by $35 \%$, compared with $12 \%$ in the laissez-faire scenario. This is because in the laissez-faire scenario the demand for regular goods does not fall much so those workers can continue to produce and be paid. This is true also for the $C$-intensive flexible occupations, whose earnings are also affected by the lockdown because of imperfect substitutability across occupations in production. In contrast, the $S$-intensive occupations are hit similarly hard in both cases.

Lockdown decomposition In Figure 9 we decompose the dynamics in the lockdown scenario into contributions from the social sector and workplace components.

The top row of Figure 9 shows that the workplace labor lockdown is somewhat more effective at suppressing infections, and hence deaths than the social sector lockdown, but comes with larger economic cost (compare the red and green lines in the second panel). The reason is that by limiting the amount of onsite work across the board, the workplace lockdown prevents those employed in rigid occupations in the $C$ sector from working and, through imperfect substitutability across occupations, heavily affects total production in a sector of the economy that accounts for $3 / 4$ of GDP.

The decompositions in Figure 9 also highlight the dynamic trade-offs involved with different types of lockdowns. In the absence of further lockdown orders, an initial lockdown that 

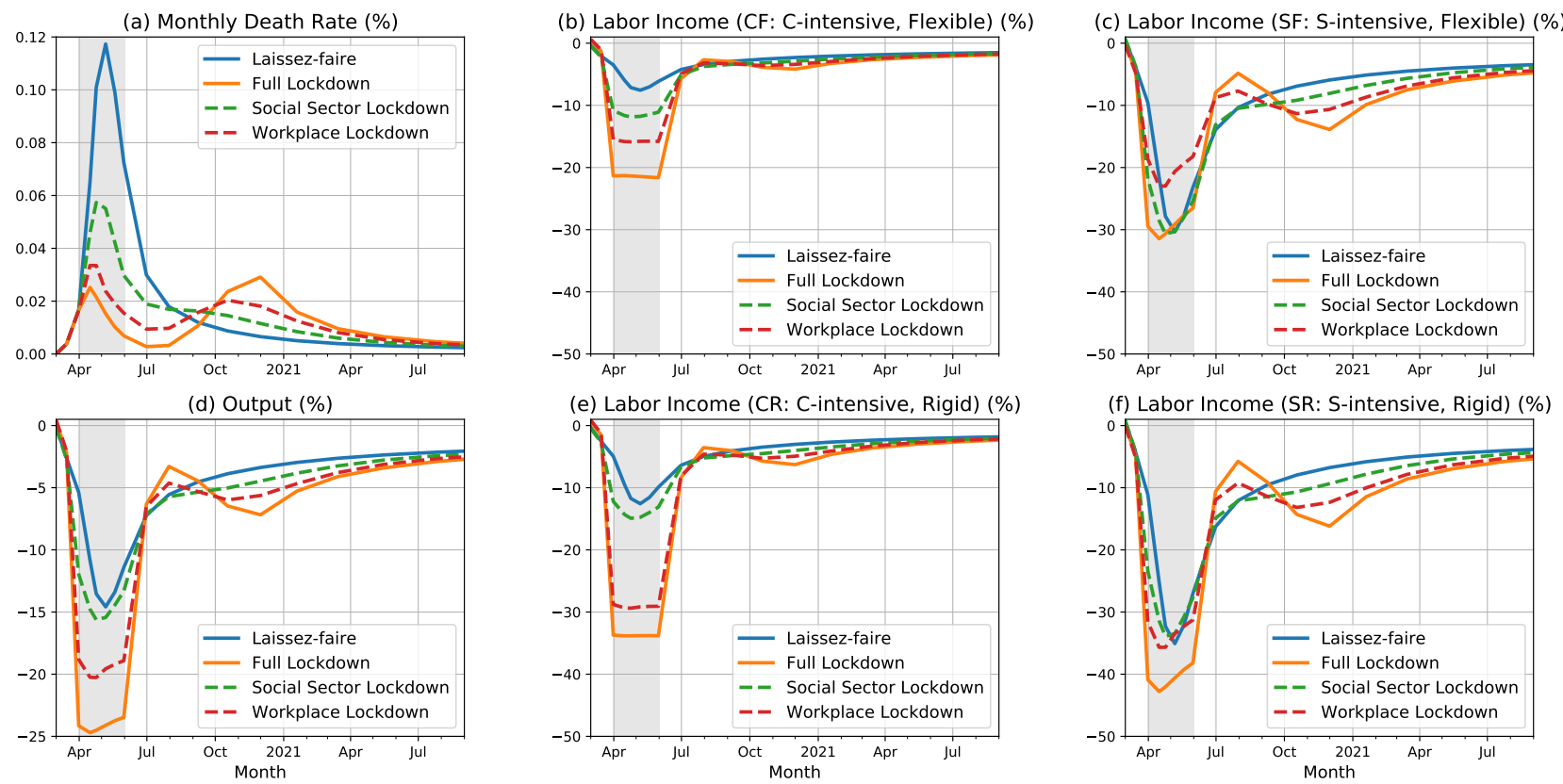

Figure 9: Role of different lockdown components

is more effective at lowering infections during the first half of 2020 comes at the cost of not only a deeper contraction, but also a larger second wave of infections and deeper associated recession in 2020:Q4, and a slower recovery in 2021 (compare solid orange and dashed green lines).

Pandemic possibility frontier (PPF) Figure 10 displays a distributional pandemic possibility frontier that offers a more systematic analysis of the tradeoffs between health and economic outcomes under different lockdown policies. Each vertical segment on the frontier corresponds to a lockdown scenario of different length. Longer lockdowns are those towards the left of the frontier, with fewer total deaths; shorter lockdowns are those towards the right of the frontier, with more total deaths. The thick dash-dot line traces out the combinations of mean economic welfare costs and total death rates that are achievable with lockdowns of different lengths. The shaded regions indicate different percentiles of the economic welfare cost distribution corresponding to each lockdown length. The laissez-faire and baseline 2month lockdown discussed above are indicated on the frontier.

Regardless of the length of lockdown, the economic welfare costs of the pandemic are large and heterogeneous. In the baseline 2-month lockdown, the average economic welfare cost is around 3.4 times monthly income, with a 90-10 percentile ratio that ranges from less than 2.2 times to nearly 4.5 times monthly income. Both the size and heterogeneity in the economic costs of the pandemic increase with the length of the lockdown. The mean cost of a 12-month lockdown is nearly 7 times monthly income, with a $90-10$ ratio of 4.5 to 8.5 times 


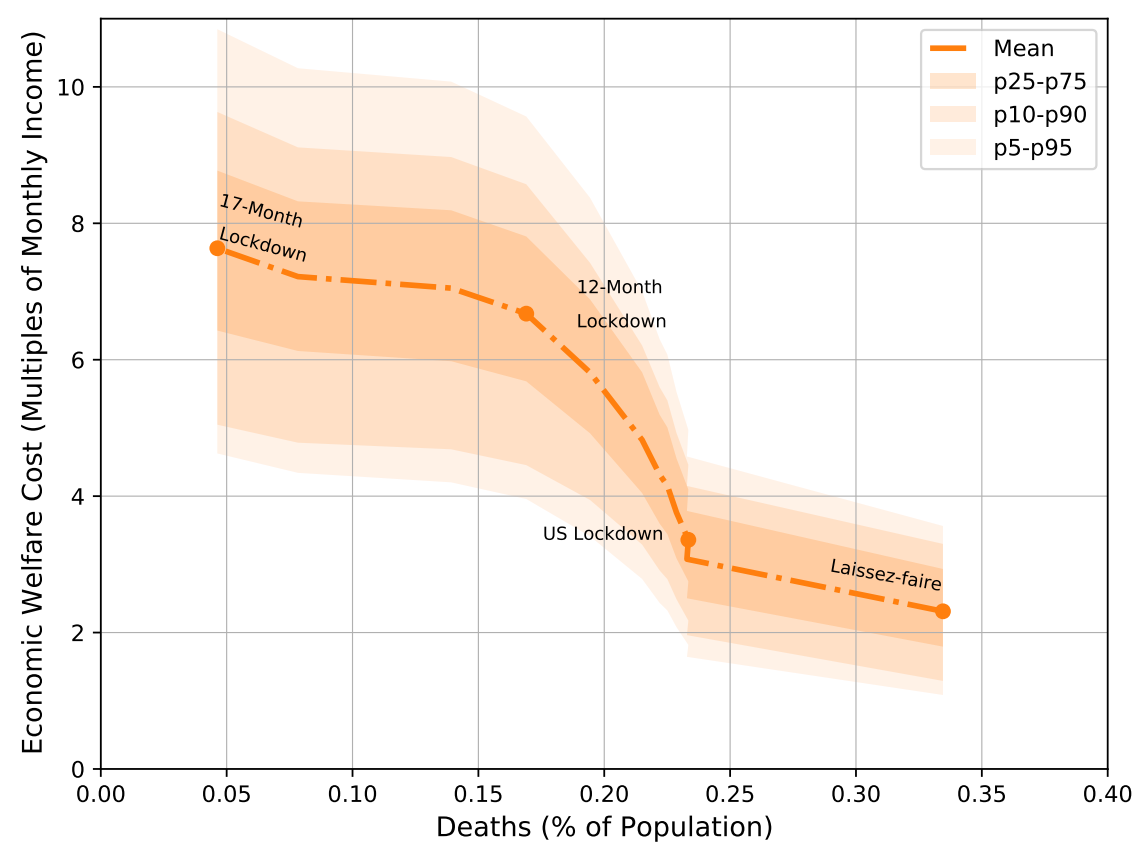

Figure 10: Counterfactuals with lockdown but no fiscal policy: frontier

monthly income. Therefore both mean and dispersion of economic losses roughly double as the lockdown is extended from 2 to 12 months. ${ }^{35}$

The non-convex shape of the mean frontier reflects the different mechanisms through which the lockdown affects the spread of the virus at different durations. Moving from the rightmost point of the frontier (laissez-faire), the frontier is initially relatively flat, reflecting the fact that short lockdowns (less than 2 months) induce relatively small economic costs but drastically reduce deaths. This sizable reduction in deaths is due to two effects of such short lockdowns: (i) preventing the ICU capacity constraint from binding; and (ii) buying time for people to learn best-practice behaviors so that $R_{0}$ falls.

Longer lockdowns (between 2 and 12 months) incur a less favorable trade-off between deaths and economic welfare, as reflected in the steeper portion of the frontier. This follows from the epidemiological dynamics inherent in SIR models. In the absence of ICU constraints and declines in $R_{0}$, the best that a temporary lockdown can do is to eliminate pandemic overshoot, i.e. to reach the herd immunity threshold without the virus still circulating (see e.g. Rachel, 2020; Moll, 2020). This limits the number of lives that can be saved by lengthening the lockdown, but the economic costs continue to increase steeply with the duration of the lockdowns.

\footnotetext{
${ }^{35}$ Table 9 in Appendix D summarizes cumulative deaths and welfare costs at different points of the pandemic possibility frontiers for these experiments as well as all the others in the paper.
} 
(a) Economic Welfare Cost

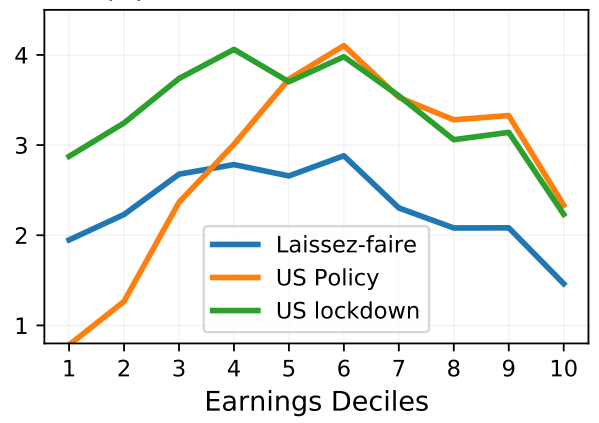

(c) Fiscal - Lockdown

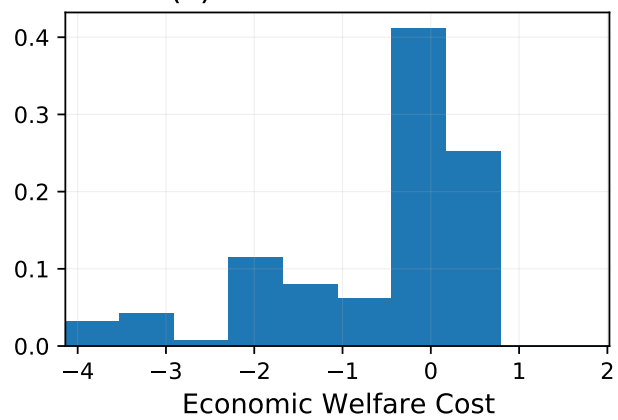

(b) Lockdown - Laissez-faire

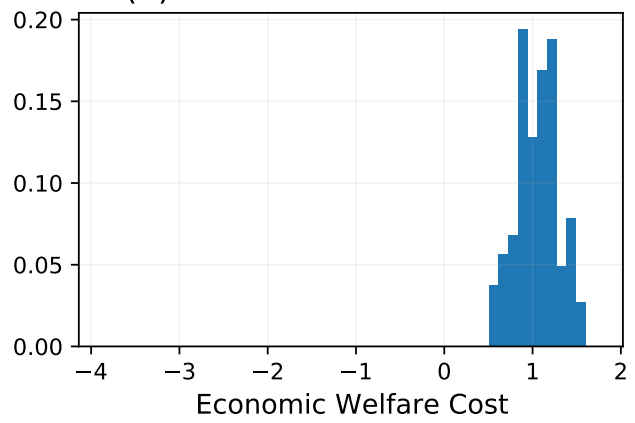

(d) Fiscal - Laissez-faire

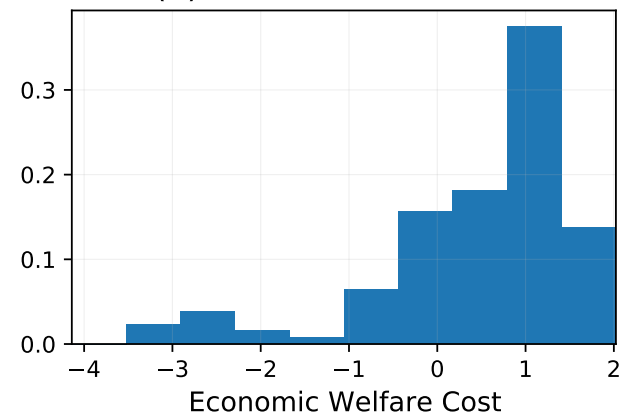

Figure 11: Panel (a): economic welfare losses by initial position in the distribution of earnings. Panel (b): distribution of economic welfare losses (multiples of monthly income) from imposing the lockdown relative to the laissez faire. Panel (c): from lockdown plus the fiscal stimulus relative to the lockdown only. Panel (d): from lockdown plus the fiscal stimulus relative to the laissez-faire.

As the arrival of the vaccine nears, additional lives can be saved by relatively short extensions of the lockdown that incur little additional economic costs. This is why the frontier flattens as the lockdown is extended beyond 12 months.

Welfare cost distribution Panel (a) of Figure 11 illustrates the distribution of economic welfare losses across the earnings distribution. Everyone loses from the pandemic, both under lassez-faire and under lockdown, but households who lose the most, perhaps surprisingly, are always those in the middle of the distribution. The economic losses of the poorest ones are limited because the main source of their income is not labor, but government transfers which remain unchanged. ${ }^{36}$

Comparing the green and the blue line in panel (a) reveals that the economic losses of the lockdown are quite uniform across the distribution. Panel (b) confirms this impression: the entire distribution of economic welfare losses is compressed between 0.5 and 1.5 of monthly income, with a mean economic loss around 1.

\footnotetext{
${ }^{36}$ Combining this analysis with that of the pandemic possibility frontier implies that households at the top of the band in Figure 10 are those around the 30th percentile and households at the bottom of the band are those in the 99 th percentile.
} 
(a) Transfers (\% of Quarterly GDP)

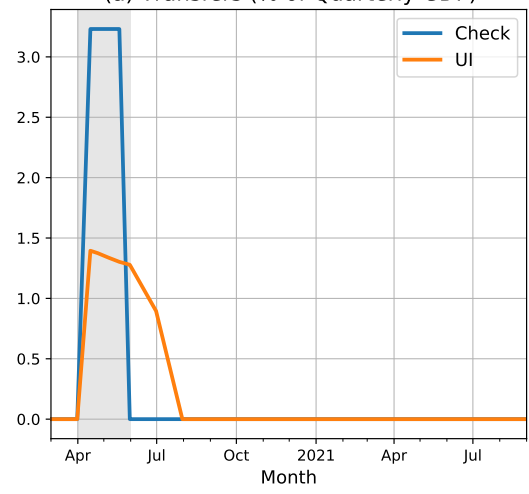

(b) PPP Subsidies (\%)

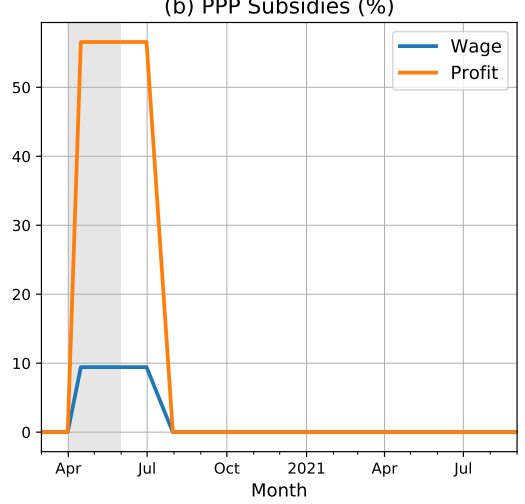

(c) Withdrawal Cost (\%)

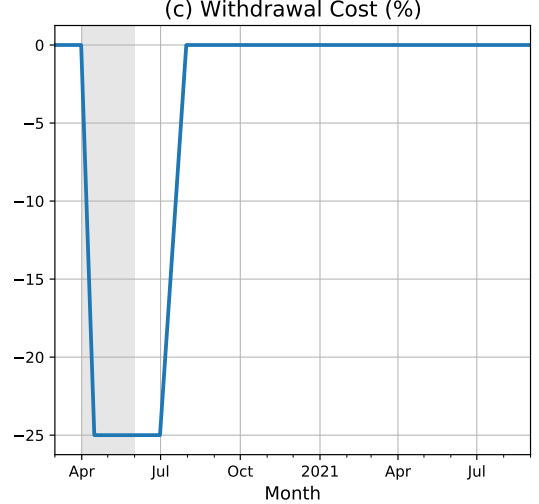

Figure 12: Components of fiscal stimulus package in model

\subsection{Fiscal Stimulus Scenario}

In this section we add to the lockdown scenario a set of economic stimulus measures that mimic the Coronavirus Aid, Relief, and Economic Security (CARES) Act. The simulations in this section are intended to be compared with US data and are our point of departure for counterfactual stimulus and containment strategies.

Modeling the CARES act We focus on the four most important components of the CARES act for household welfare. Appendix C contains a detailed description of these different stimulus policies and how we incorporate them in our model economy. Here we provide only a summary. ${ }^{37}$

(i) The Economic Impact Payments (EIP) program consisted of one-time stimulus payments with amounts which depended on family size and were phased out at high income levels. To match the total outlays reported by the Department of Treasury $(\$ 260 \mathrm{~B})$, we set the payment per household to $\$ 1,900$. We model these payments as flow transfers paid out evenly over 1.5 months. This allows us to capture delays that occurred during the rollout of the program and heterogeneity in the exact timing of the payments.

(ii) Several expansions to the Unemployment Insurance (UI) program consisted of additional payments to unemployed workers and extended eligibility. We model UI as transfers that compensate for the shortfall of individuals' labor incomes relative to their steady state values, based on the replacement rates calculated by Ganong et al. (2020). For low-income households these replacement rates exceeded 100\%.

\footnotetext{
${ }^{37}$ The CARES act was passed by Congress at the end of March. In our simulations, we assume that the policy is implemented on April 15.
} 

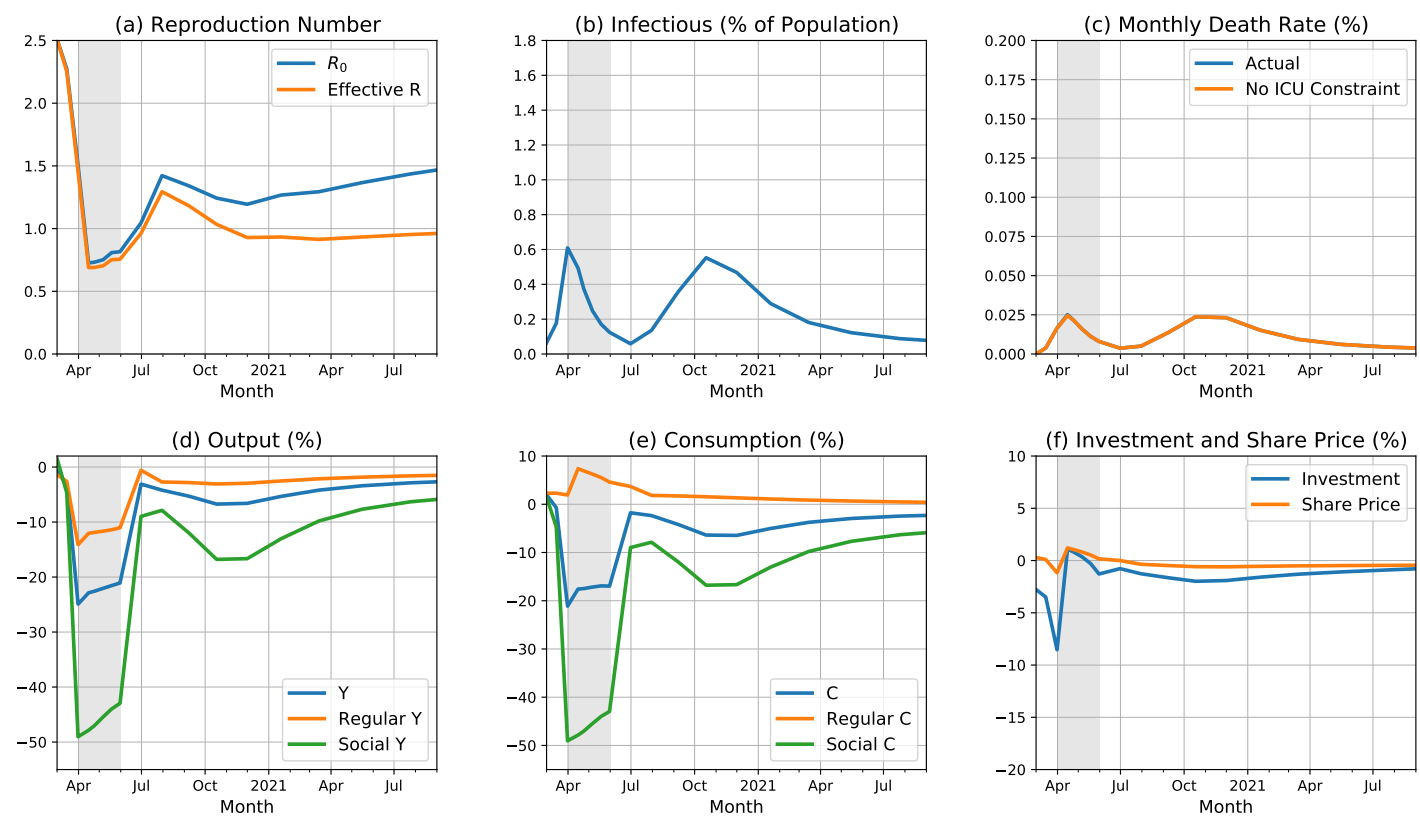

(g) Hours (\%)
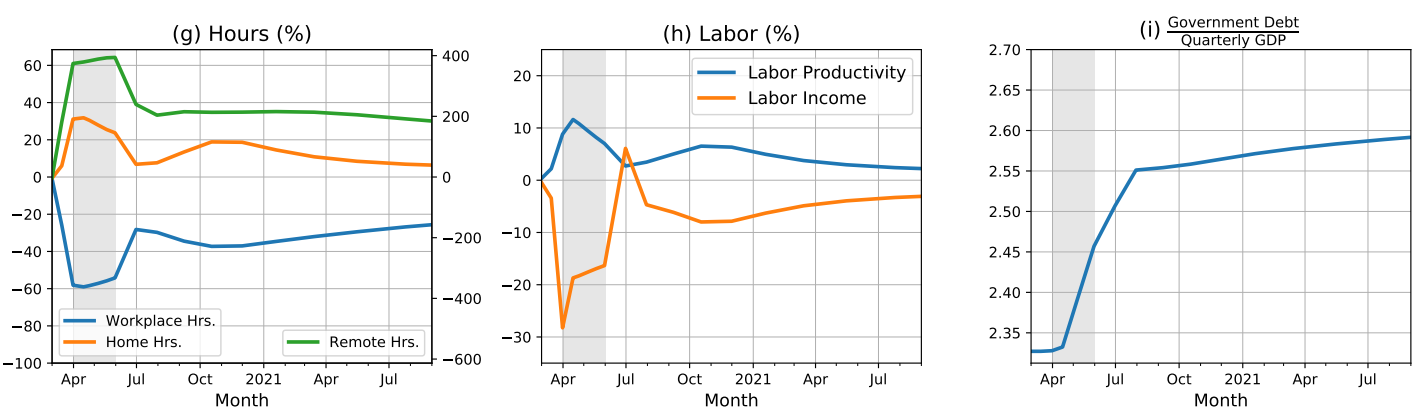

Figure 13: Lockdown plus fiscal stimulus: dynamics of key variables

(iii) The Paycheck Protection Program (PPP) was intended as an employment subsidy. Some researchers, however, have argued that PPP may not have been as effective at protecting employment as the program's name suggests (see e.g. Chetty et al., 2020; Granja et al., 2020) since firms were not required to demonstrate that funds provided under the program were used to finance payroll expenses for workers that would have been otherwise laid-off. We therefore model the PPP as part wage subsidy and part profit subsidy $\left(\varsigma_{w t}, \varsigma_{\pi t}\right.$ in the model), with each component amounting to $50 \%$ of the PPP's $\$ 669$ billion budget.

(iv) Tax penalties for retirement account withdrawals were temporarily waived and withdrawal limits were relaxed. We model this policy as a reduction in the scale parameter $\chi_{1}$ in the adjustment cost function in equation (20).

Figure 12 plots the magnitudes and timing of these four elements of the CARES act that we feed into the model. In line with the data, components (ii)-(iv) expire on August 1st. 
(a) Effective $R$
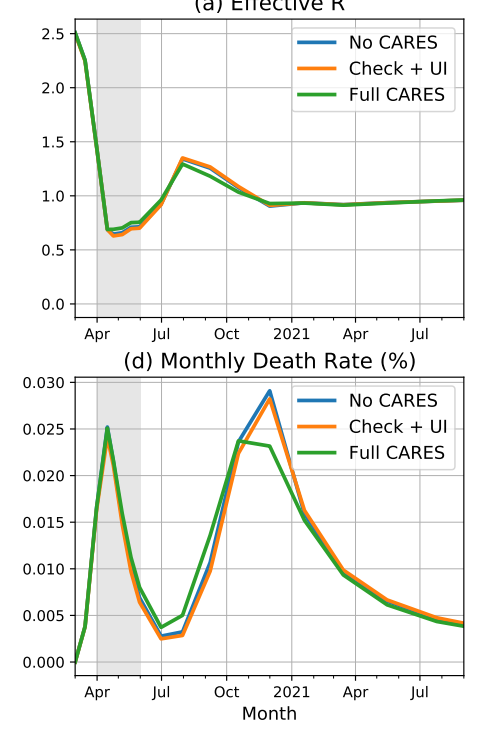

(b) Labor Income (\%)

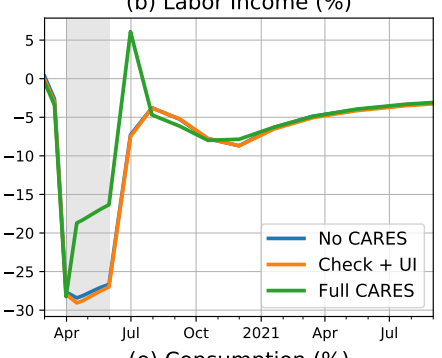

(e) Consumption (\%)

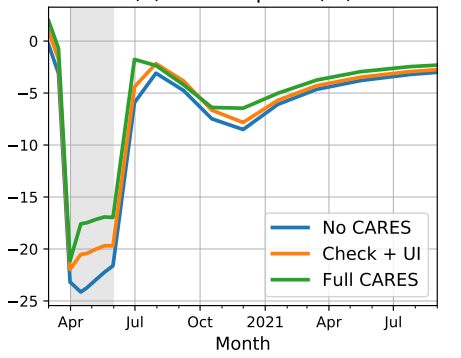

(c) Workplace Hours (\%)

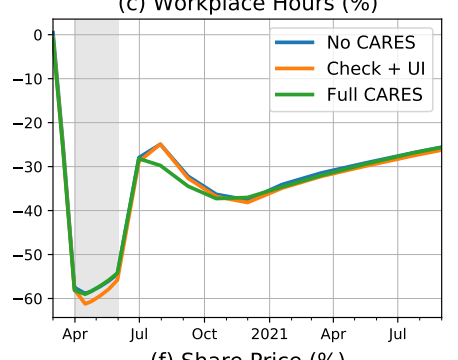

(f) Share Price (\%)

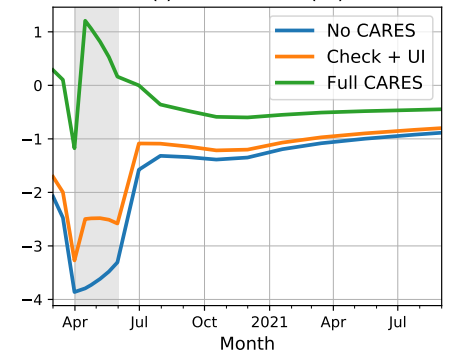

Figure 14: Effect of different stimulus components

CARES act decomposition Figure 13 displays the analogous aggregate dynamics to those in Figures 4 and 7 for the model with fiscal stimulus. Figure 14 plots a subset of these variables alongside their counterparts in the scenario with a lockdown but no stimulus, together with an intermediate stimulus package that contains only the EIP payments and expanded UI benefits.

The top two panels in Figure 14 show that the stimulus package has barely any effect on the initial dynamics of the virus. However, the effective reproduction number is slightly lower in the second wave, which just prevents the ICU constraint from binding and lowers fatalities in the second wave. The reason for the lower transmission rate is that the PPP raises asset prices. The higher asset prices lead people to work fewer hours in the workplace due to a wealth effect. Lower workplace hours leads to fewer infections

The impact of the stimulus package on economic aggregates is substantial. Both the transfer programs (EIP, UI) and PPP boost aggregate consumption throughout the lockdown and in its immediate aftermath. We revisit these effects on consumption below in our discussion of the distributional dynamics of consumption. The CARES act boosts consumption by around 6 percentage points, with about 4 points coming from PPP and the remainder from UI and EIP.

Because we model the PPP as part labor subsidy and part profit subsidy, its two main effects are on labor income and firms' profitability. Figure 14(b) shows that PPP reduces the fall in labor income by around half, and Figure 14(f) shows that the fall in the stock market by around 4 percentage points.

The costs of the stimulus package can be seen in the large increase in government debt Figure 13(i). After eighteen months the debt-GDP ratio increases by about $12 \%$ above its 


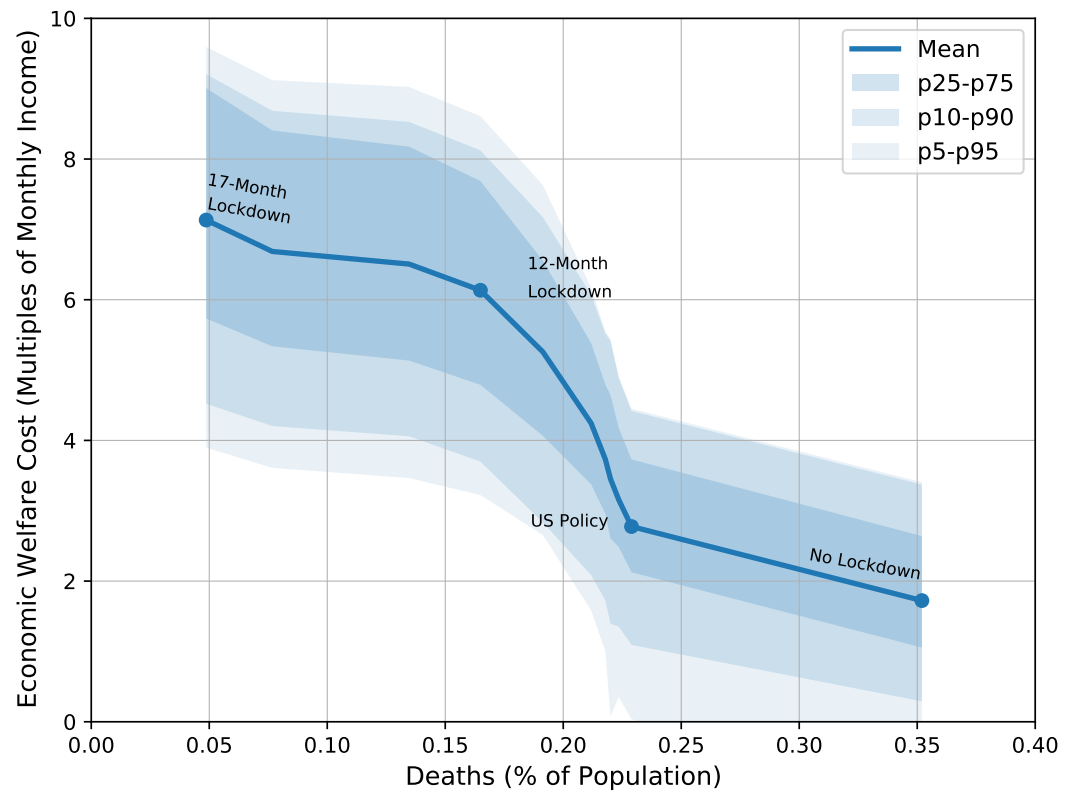

Figure 15: Lockdown plus fiscal stimulus: distributional frontier

pre-pandemic level, compared with an increase of $3 \%$ without the CARES act.

Pandemic possibility frontier Figure 15 displays the pandemic possibility frontier for lockdowns of different lengths in the presence of the stimulus package. The stimulus package does not alter the shape of the frontier, but it shifts down the frontier and widens the distribution of economic costs, especially for short lockdowns, by substantially lowering the welfare losses for about a quarter of households.

This comparison is most clearly seen in Figure 1 in the Introduction. The downward shift in the frontier reflects the role of the stimulus package in raising household consumption. The stimulus package lowers the average economic cost of the lockdown by around $20 \%$, from 3.4 times monthly income to 2.7 times monthly income. The success of the policy is the mirror image of the failure of Ricardian equivalence in the model.

The top-right panel of Figure 11 reports the distribution of welfare losses (negative numbers are gains) from the combination of lockdown and fiscal stimulus relative to a scenario without fiscal stimulus. Almost all households gain from the CARES Act. The top-left panel of the figure clarifies that gains are concentrated below the median. The CARES act was highly redistributive. It is especially interesting that the poorest tercile of the distribution is economically better off even compared to laissez-faire (these are the households with negative values in the bottom-right panel). Thus, under the combined lockdown and fiscal stimulus policy, the bottom quintile of the earnings distribution are better off in terms of both lives 
(a) Labor Income (\%)

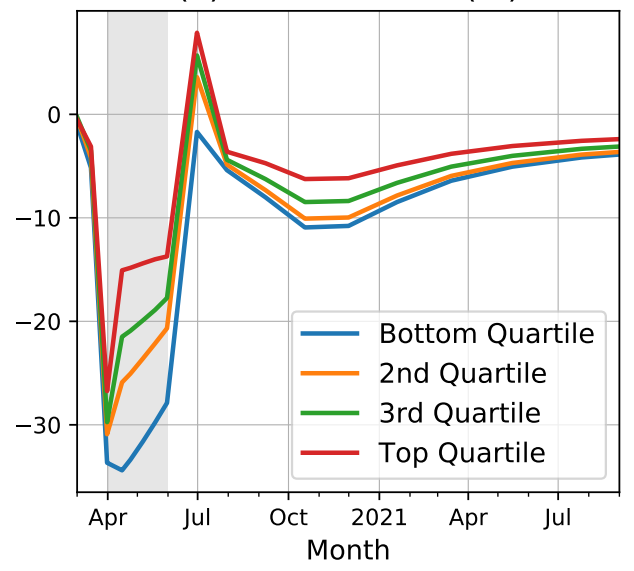

(b) Consumption (\%)

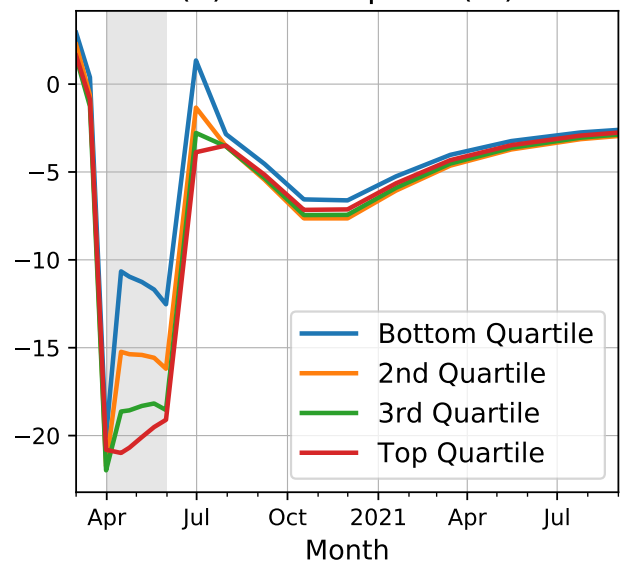

Figure 16: Labor income and consumption across pre-pandemic income distribution

and economic welfare than in the laissez-faire scenario.

Distribution of consumption and earnings We can use our model to interpret recent empirical evidence on household labor income and consumption in the early stages of the pandemic in the US. Cajner et al. (2020) find that labor incomes have fallen most for households at the bottom of the income distribution and have remained low. These households disproportionally work in hospitality and other rigid, $S$-intensive occupations. At the same time, Cox et al. (2020) and Chetty et al. (2020) find that consumption expenditures of poor households have recovered more quickly than expenditures of rich households.

Our model reproduces these apparently contradicting patterns of consumption and labor income, and offers an intuitive explanation. Figure 16 displays the paths of average labor incomes and consumption in each quartile of the income distribution, over the first four months of the pandemic. As in the data, in the model labor incomes fall most for the lowest quartile of the pre-pandemic income distribution and remain persistently low. Also as in the data, the drop in expenditures is much more uniform across the distribution, but recovers fastest for the households in the bottom quartile. The reason, as illustrated in Figure 17, is that the stimulus package had very heterogeneous effects across the income distribution.

Figure 17 decomposes the dynamics of labor income, total income and consumption into contributions from each major component of the stimulus program, for the top and bottom quartiles of the income distribution.

Panels (a) and (d) shows PPP leads to earnings gains for workers across the income distribution. UI benefits, instead, slightly disincentivizes labor supply at the bottom of the distribution, where replacement rates widely exceeded 100\%. Together, the CARES act mitigated the fall in earnings for all workers, but the drop in labor earnings was still at least 
(a) Labor Income (\%)

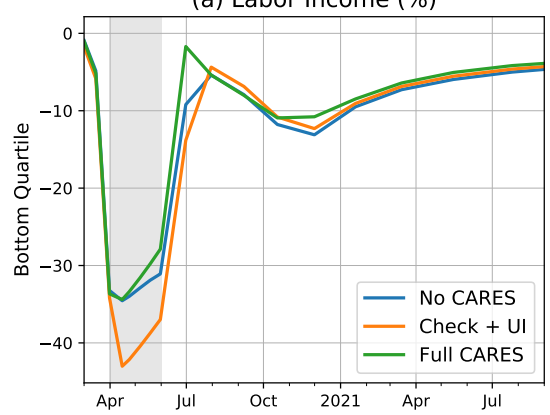

(d) Labor Income (\%)

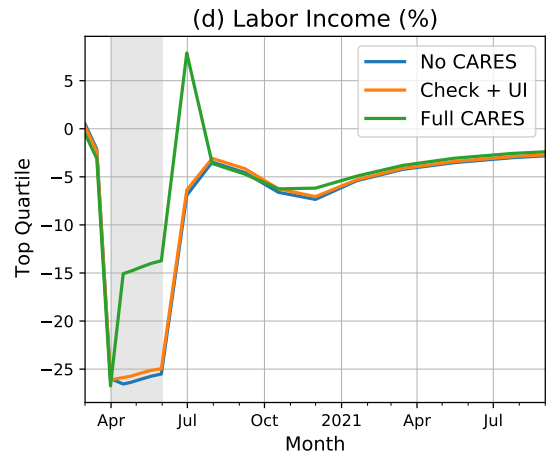

(b) Total Income (\%)

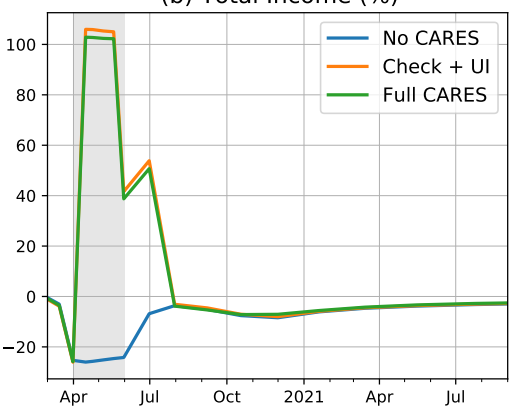

(e) Total Income (\%)

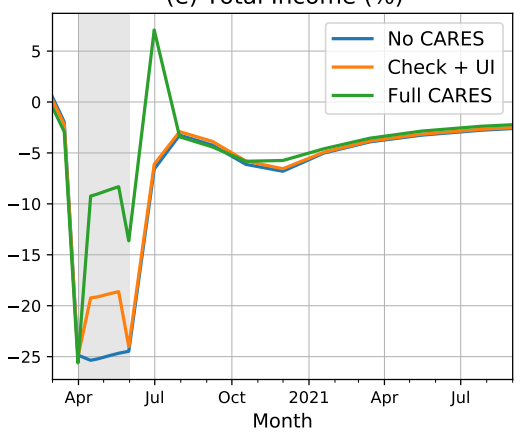

(c) Consumption (\%)

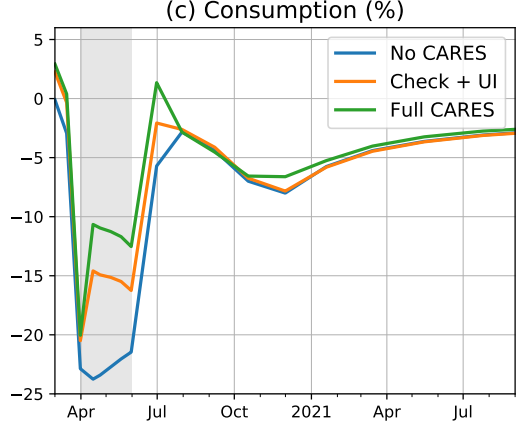

(f) Consumption (\%)

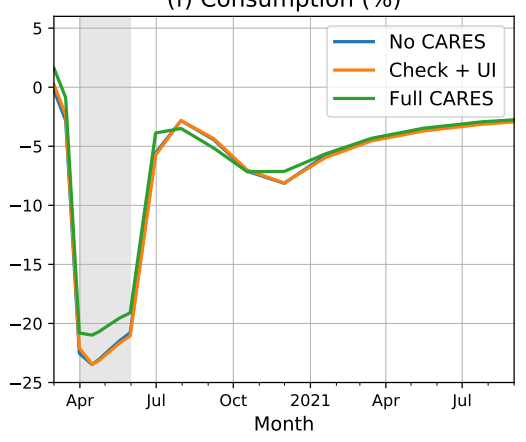

Figure 17: Effect of different stimulus components across pre-pandemic income distribution

10 percentage points deeper at the bottom of the earnings distribution. Panels (b) and (f) show the stark contrast in the dynamics of total income (including fiscal transfers) between the top and bottom quartiles of the income distribution. Through the lens of our model, the combined effect of the various elements of the CARES Act is that income-poor households experienced large increases in their total incomes. ${ }^{38}$ Since many of these households are liquidity constrained, their consumption expenditures follow income closely: they first fall and then rise (panel (c)). Richer households are rarely liquidity constrained and, as a result, display more pronounced forward-looking behavior. Because the economic outlook is bleak, these households cut consumption and save a larger fraction of their income, including the additional one from the government. These patterns are consistent with empirical evidence in Baker et al. (2020) and Coibion et al. (2020a) that recipients of stimulus checks consumed a sizable fraction of them in the first weeks after receipt, and that households with lower earnings, greater income drops, and lower levels of liquidity displayed stronger spending responses.

\footnotetext{
${ }^{38}$ When interpreting the large percentage increase it is important to keep in mind that the average starting income of this population group is very low, so large percentage increases still corresponds to small absolute amounts.
} 


\subsection{Smart Containment and Fiscal Policies}

So far, we have only analyzed workplace and social sector lockdowns as policies to contain the virus. These forms of blunt lockdowns have been the main policy instrument used by the U.S. and other countries to contain the spread of the virus. ${ }^{39}$ Blunt lockdowns have the advantage of being both (i) quickly implementable, and (ii) effective at rapidly curtailing infections when ICU use is near capacity. In the initial phase of an unexpected epidemic they are thus a sensible policy response. However, blunt lockdowns also have the disadvantage of being costly in terms of economic welfare, in the absence of adequate social insurance provision. Are there other instruments that can achieve a better trade-off between lives and the economy, as measured by a flatter and more inward locus for the pandemic possibility frontier? In this section, we explore three alternatives.

Smart exemptions from workplace lockdown As with the lockdowns implemented in the U.S. and most of Europe, the workplace lockdown in our baseline scenario applies to all non-essential business, including firms in the $C$-sector. However, based on the findings of Section 4.2, an economy-wide workplace lockdown might be excessive.

Panel (b) in Figure 18 plots the pandemic possibility frontier (PPF) for a workplace lockdown that exempts $C$ sector businesses and allows their employees to work on-site. The main effect of this loosening is to change the labor supply of workers in rigid $C$-intensive occupations. Panel (a) shows how the PPF compares to the PPF in the full lockdown scenario. This looser lockdown generates a flatter PPF, particularly at long durations. But even with only a 2 months lockdown, this looser lockdown would have saved roughly the same number of lives with $10 \%$ lower welfare costs. One limitation of the looser lockdown, however, is that the maximum achievable reduction in deaths is smaller than for the full lockdown.

Pigouvian taxes rebated smartly The virus generates a negative externality: individuals do not internalize that when they consume social goods or work in the workplace, they risk contracting the virus, which imposes costs on other individuals. These costs are due to (i) higher disutility of work and lower utility of social consumption (since these utilities depend on the average death rate); (ii) higher probability of contracting the virus and being hospitalized and hence unable to work and consume; and (iii) lower residual ICU capacity and so possibly higher death rates for the critically ill.

A natural remedy for such negative externalities is a Pigouvian tax on either social consumption or on-site work. ${ }^{40}$ However, in a model with heterogeneity and market incom-

\footnotetext{
${ }^{39} \mathrm{An}$ important exception is the use of border closures in combination of with test and tracing in a handful countries, such as Australia and New Zealand).

${ }^{40}$ Note that this is the opposite of the U.K.'s "Eat Out to Help Out" policy, which subsidizes social
} 
(a) Comparison

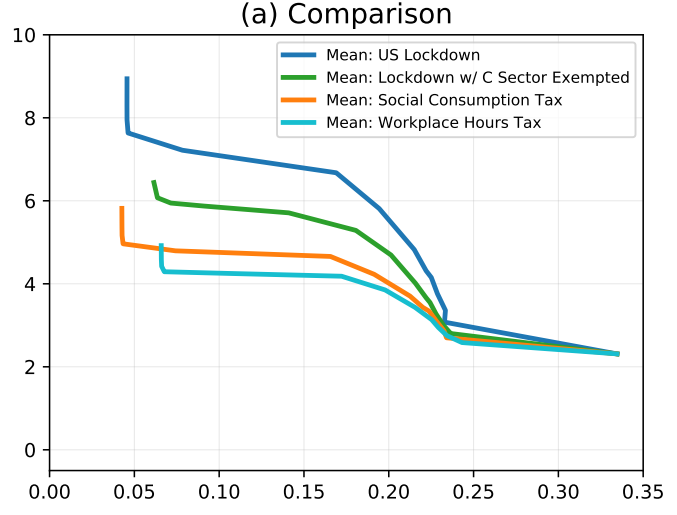

(c) Social Consumption Tax

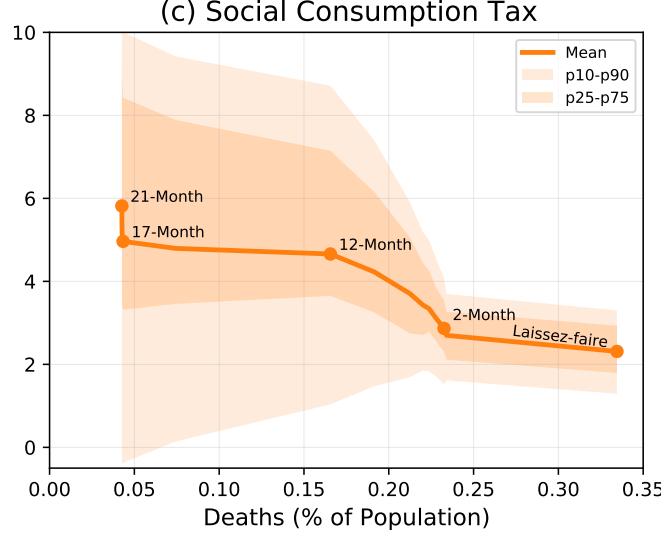

(b) Lockdown w/ C Sector Exempted

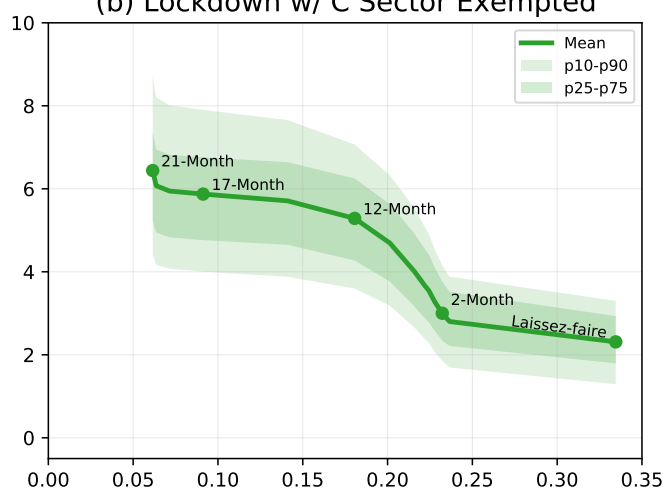

(d) Workplace Hours Tax

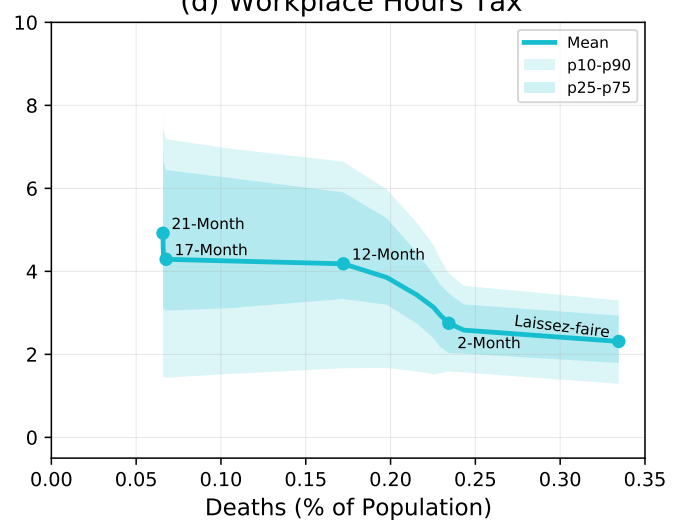

Figure 18: Panel (a): mean pandemic possibility frontier (PPF) for three "smart policies" and for the baseline lockdown. Each dot on the frontier represents a different duration for the policy. Panel (b): $C$-intensive occupations exempted from the lockdown. Panel (c): Pigouvian tax of 30\% on social consumption with revenues rebated to the $S$-intensive occupations. Panel (d): Pigouvian tax of $30 \%$ on workplace earnings with revenues rebated to the rigid occupations.

pleteness, either tax is particularly bad for a subset of individuals - in the case of a tax on social consumption, those working in the social sector; in the case of a tax on on-site work, those in rigid occupations. We offset these costs by rebating the revenues lump-sum to the affected workers.

Panel (c) of Figure 18 traces the PPF for a 30\% tax on social consumption that is kept in place for different durations. The revenues from this tax are rebated to workers in $S$ intensive occupations. So, for example, instead of the government mandating the closure of restaurants, bars, gyms and hair salons, the government imposes a $30 \%$ tax on the sales of these establishments, and rebates the revenues to both flexible and rigid workers in these businesses.

The social consumption tax generates a PPF (orange line in panel (a)) that is even flatter than the PPF from the lockdown with smart exemptions (green line in panel (a)), consumption. 
with most of the gain in trade-off coming at long durations. However, keeping the tax on social consumption in place for an extended period leads to extremely unequal outcomes across the distribution of households. The reason is that although the targeted rebate is successful at containing the economic losses of workers employed in $S$-intensive occupations, the cost of the tax falls heavily on households in $C$-intensive occupations, especially those in rigid jobs who cut their workplace hours for fear of contracting the virus.

An alternative Pigouvian tax policy is to impose a tax on hours worked in the workplace and to rebate the proceeds to workers in rigid occupations. This tax targets the labor supply margin as the source of the negative externality, as opposed to the social consumption margin. Panel (d) of Figure 18 traces the PPF for a 30\% tax on workplace hours with different durations. This policy generates the flattest PPF. With a tax on workplace hours in place for 2 months, the mean economic welfare loss is about 2 times monthly income, which is about the same as in the laissez faire scenario, but with a substantially smaller number of deaths - by around $0.1 \%$ of the population.

The distributional outcomes of the tax on workplace hours are also unequal at long durations. Workers in the rigid occupations gain the most from this policy, because it essentially insures their labor earnings. Workers in the flexible occupations gain the least, not because of the direct effect of the tax (which they don't pay because they work from home), but because their productivity suffers due to the low labor supply of their colleagues in rigid occupations.

Figure D1 plots PPFs by occupations for all these alternative policy simulations alongside those for the lockdown scenario with and without fiscal stimulus.

Summarizing, an important lesson from these experiments is that there exist targeted policies which offer a more favorable average trade-off between lives and livelihoods than blunt lockdowns. There are two important limitations to these policies which would need to be addressed if they were implemented in practice. First, targeted lockdown and tax policies entail a more unequal distribution of economic welfare costs. Second, there are limits to the total reduction in deaths that can be achieved by different policies, as indicated by the vertical segments in panel (a) of Figure 18. An example we have explored that illustrates both of these features is to exclude essential occupation from the tax on workplace hours in panel $(\mathrm{d})$. With this alternative policy, the dispersion in economic welfare costs is substantially reduced but so is the maximum possible reduction in deaths that can be achieved by extending the duration of the tax.

\section{Conclusion}

We provide a quantitative analysis of the trade-offs between lives and economic outcomes associated with the COVID-19 pandemic, under the lockdown and fiscal policies implemented 
in the U.S., as well as under alternative counterfactual policy scenarios. We focus on the distributional implications of these policies across workers and households. Different individuals have different degrees of economic exposure and vulnerability to the pandemic. Heterogeneity in exposure is related to the extent to which an individual works in a rigid occupation and/or and occupation that is used intensively in the production of social goods and services. Heterogeneity in vulnerability is related to households' access to liquid savings and eligibility for government transfers. We find that in U.S. data, the most exposed individuals are also the most vulnerable, which opens the door to very unequal economic consequences of the pandemic.

Our model simulations suggest that a representative household perspective of the pandemic that ignores this heterogeneity would miss some first-order effects of both the lockdown and fiscal policies. The economic welfare costs of the pandemic are large and heterogeneous regardless of the policy response. Even smart containment and fiscal policies that offer a more favorable trade-off in terms of mean outcomes entail very uneven outcomes. Thus, whereas most of the emphasis in public debate has been on the extent of the trade-off that governments face in terms of lives and livelihoods, we emphasize the equally important and inescapable choice over which parts of the population should carry the heaviest burden of the economic costs. Through our focus on a distributional pandemic possibility frontier, our paper offers a framework to integrate these different aspects of the policy trade-offs.

Partly because of a constraint on space, and partly because we are not aware of data that can be used for calibration, we have not run counterfactuals where some of the funds used for fiscal support are diverted toward investing in health outcomes. Such investments might include education campaigns about wearing face masks and physical distancing, widespread testing and tracing, better treatments for COVID-19 and vaccine development. Through the lens of our model such investments not only improve health outcomes but also have positive distributional effects, because more effective suppression of the virus enables workers in rigid occupations and the social good sector to return to work sooner.

Finally, looking ahead, our model predicts that, in the absence of a tight lockdown in the Fall of 2020, the U.S. will experience a second wave of the virus and another (milder) recession: the recovery will be $W$ shaped and very prolonged. Moreover, the distributional implications of the second wave will be much closer to those observed under our laissez-faire counterfactual, with the economic costs falling more heavily on the most vulnerable parts of the population, and thus quite different from the distribution of costs during the first wave in the Spring of 2020. This discrepancy calls for a distinct, more targeted, policy response. 


\section{References}

Acemoglu, D., V. Chernozhukov, I. Werning, and M. D. Whinston (2020): "A MultiRisk SIR Model with Optimally Targeted Lockdown," NBER Working Papers 27102, National Bureau of Economic Research, Inc.

Adams-Prassl, A., T. Boneva, M. Golin, and C. Rauh (2020): "Inequality in the Impact of the Coronavirus Shock: Evidence from Real Time Surveys," IZA Discussion Papers 13183, Institute of Labor Economics (IZA).

Aguiar, M. And E. Hurst (2007a): "Life-cycle prices and production," American Economic Review, 97, 1533-1559.

(2007b): "Measuring trends in leisure: The allocation of time over five decades," The Quarterly Journal of Economics, 122, 969-1006.

Akbarpour, M., C. Cook, A. Marzuoli, S. Mongey, A. Nagaraj, M. Saccarola, P. Tebaldi, S. Vasserman, And H. Yang (2020): "Socioeconomic Network Heterogeneity and Pandemic Policy Response," University of Chicago, Becker Friedman Institute for Economics Working Paper.

Alfaro, L., E. Faia, N. Lamersdorf, And F. Saidi (2020): "Social Interactions in Pandemics: Fear, Altruism, and Reciprocity," CEPR Discussion Papers 14716, C.E.P.R. Discussion Papers. Alon, T. M., M. Doepke, J. Olmstead-Rumsey, and M. Tertilt (2020a): "The Impact of COVID-19 on Gender Equality," Tech. rep., National Bureau of Economic Research.

Alon, T. M., M. Kim, D. Lagakos, And M. VanVuren (2020b): "How Should Policy Responses to the COVID-19 Pandemic Differ in the Developing World?" Working Paper 27273, National Bureau of Economic Research.

Alvarez, F. E., D. Argente, and F. Lippi (2020): "A Simple Planning Problem for COVID-19 Lockdown," NBER Working Papers 26981, National Bureau of Economic Research, Inc.

Alves, F., G. Kaplan, B. Moll, and G. L. Violante (2020): "A Further Look at the Propagation of Monetary Policy Shocks in HANK," .

AtKeson, A. (2020): "What Will be the Economic Impact of COVID-19 in the US? Rough Estimates of Disease Scenarios," Staff Report 595, Federal Reserve Bank of Minneapolis.

Azzimonti, M., A. Fogli, F. Perri, And M. Ponder (2020): "Social Distance Policies in ECON-EPI Networks," Presentation slides.

Baker, S. R., R. A. Farrokhnia, S. Meyer, M. Pagel, and C. Yannelis (2020): "Income, Liquidity, and the Consumption Response to the 2020 Economic Stimulus Payments," NBER Working Papers 27097, National Bureau of Economic Research, Inc.

Baqaee, D., E. Farhi, M. Mina, and J. Stock (2020): "Evaluating the Economics and Epidemiology of Strategies for Reopening the Economy," .

Baqaee, D. R. And E. FArhi (2020): "Nonlinear Production Networks with an Application to the Covid-19 Crisis," CEPR Discussion Papers 14742, C.E.P.R. Discussion Papers.

Bar-On, Y. M., A. Flamholz, R. Phillips, And R. Milo (2020): "A Quantitative Compendium of COVID-19 Epidemiology," Tech. rep.

Barrero, J. M., N. Bloom, And S. J. Davis (2020): "Covid-19 is also a Reallocation Shock," Tech. rep., National Bureau of Economic Research.

Bayer, C., B. Born, R. Luetticke, And G. Müller (2020): "The Coronavirus Stimulus Package: How large is the transfer multiplier?" CEPR Discussion Papers 14600, C.E.P.R. Discussion Papers.

Berger, D., K. Herkenhoff, and S. Mongey (2020): “An SEIR Infectious Disease Model with Testing and Conditional Quarantine," Working Papers 2020-017, Human Capital and Economic 
Opportunity Working Group.

Bick, A. And A. Blandin (2020): "Real Time Labor Market Estimates During the 2020 Coronavirus Outbreak," Working Paper. Arizona State University.

Brinca, P., J. B. Duarte, and M. Faria-e Castro (2020): "Measuring Sectoral Supply and Demand Shocks during COVID-19," Tech. Rep. 2020-011.

Brotherhood, L., P. Kircher, C. Santos, and M. Tertilt (2020): "An economic model of the Covid-19 epidemic: The importance of testing and age-specific policies," CEPR Discussion Papers 14695, C.E.P.R. Discussion Papers.

Cajner, T., L. D. Crane, R. A. Decker, J. Grigsby, A. Hamins-Puertolas, E. Hurst, C. Kurz, And A. YIldirmaz (2020): "The U.S. Labor Market during the Beginning of the Pandemic Recession," Brooking Papers on Economic Activity 27159.

Carroll, C. D., E. Crawley, J. Slacalek, and M. N. White (2020): "Modeling the Consumption Response to the CARES Act," Working Paper.

Carvalho, V. M., J. R. Garcia, S. Hansen, A. Ortiz, T. Rodrigo, J. V. R. Mora, AND P. Ruiz (2020): "Tracking the COVID-19 Crisis with High-Resolution Transaction Data," Working Papers 20/06, BBVA Bank, Economic Research Department.

Chetty, R., J. N. Friedman, N. Hendren, M. Stepner, and T. O. I. Team (2020): "How Did COVID-19 and Stabilization Policies Affect Spending and Employment? A New RealTime Economic Tracker Based on Private Sector Data," NBER Working Papers 27431, National Bureau of Economic Research, Inc.

Coibion, O., Y. Gorodnichenko, and M. Weber (2020a): "How Did U.S. Consumers Use their Stimulus Payments?" NBER Working Papers 27693, National Bureau of Economic Research, Inc.

Coibion, O., Y. Gorodnichenko, M. Weber, And M. Weber (2020b): "Labor Markets during the Covid-19 Crisis: A Preliminary View," CESifo Working Paper Series 8238, CESifo Group Munich.

Cox, N., P. Ganong, P. Noel, J. Vavra, A. Wong, D. Farrell, and F. Greig (2020): "Initial Impacts of the Pandemic on Consumer Behavior: Evidence from Linked Income, Spending, and Savings Data," Brookings Papers on Economic Activity.

Dingel, J. I. And B. Neiman (2020a): "How many jobs can be done at home?" Working Paper. National Bureau of Economic Research.

_ (2020b): "How Many Jobs Can be Done at Home?" NBER Working Papers 26948, National Bureau of Economic Research, Inc.

Dorn, F., S. Khailaie, M. Stoeckli, S. C. Binder, B. Lange, S. Lautenbacher, A. Peichl, P. Vanella, T. Wollmershaeuser, C. Fuest, and M. Meyer-Hermann (2020): "The Common Interests of Health Protection and the Economy: Evidence from Scenario Calculations of COVID-19 Containment Policies," medRxiv.

Eichenbaum, M. S., S. Rebelo, and M. Trabandt (2020): "The Macroeconomics of Epidemics," NBER Working Papers 26882, National Bureau of Economic Research, Inc.

Elenev, V., T. Landvoigt, and S. van Nieuwerburgh (2020): "Can the Covid Bailouts Save the Economy?" CEPR Discussion Papers 14714, C.E.P.R. Discussion Papers.

Farboodi, M., G. Jarosch, And R. Shimer (2020): "Internal and External Effects of Social Distancing in a Pandemic," NBER Working Papers 27059, National Bureau of Economic Research, Inc.

Faria E CAstro, M. (2020): "Fiscal Policy during a Pandemic," Working Papers 2020-006, Federal Reserve Bank of St. Louis.

Favero, C. A., A. Ichino, And A. Rustichini (2020): "Restarting the Economy While Saving 
Lives Under COVID-19," Tech. rep.

Ferguson, N., D. Laydon, G. Nedjati Gilani, N. Imai, K. Ainslie, M. Baguelin, S. Bhatia, A. Boonyasiri, Z. Cucunuba Perez, G. Cuomo-Dannenburg, et Al. (2020): "Report 9: Impact of non-pharmaceutical interventions (NPIs) to reduce COVID19 mortality and healthcare demand," Working Paper. Imperial College of London.

Ganong, P., P. J. Noel, And J. S. Vavra (2020): "US Unemployment Insurance Replacement Rates During the Pandemic," Working Paper 27216, National Bureau of Economic Research.

Glover, A., J. Heathcote, D. Krueger, And J. V. Rios-Rull (2020): "Health versus Wealth: On the Distributional Effects of Controlling a Pandemic," Tech. rep., Working Paper.

Gollier, C. (2020): "Cost-benefit analysis of age-specific deconfinement strategies," Tech. rep., Toulouse School of Economics.

Granja, J., C. Makridis, C. Yannelis, and E. Zwick (2020): "Did the Paycheck Protection Program Hit the Target?" NBER Working Papers 27095, National Bureau of Economic Research, Inc.

Greenstone, M., S. P. Ryan, M. Yankovich, and K. Greenberg (2014): "The Value of a Statistical Life: Evidence from Military Retention Incentives and Occupation-Specific Mortality Hazards," Unpublished manuscript.

Gregory, V., G. Menzio, And D. Wiczer (2020): "Pandemic Recession: L or V-Shaped?" Department of Economics Working Papers 20-06, Stony Brook University, Department of Economics.

Griliches, Z. (1957): "Hybrid Corn: An Exploration in the Economics of Technological Change," Econometrica, 25, 501-522.

Grimm, V., F. Mengel, And M. Schmidt (2020): "Extensions of the SEIR Model for the Analysis of Tailored Social Distancing and Tracing Approaches to Cope with COVID-19," medRxiv.

Guerrieri, V., G. Lorenzoni, L. Straub, and I. Werning (2020): "Macroeconomic Implications of COVID-19: Can Negative Supply Shocks Cause Demand Shortages?" NBER Working Papers 26918, National Bureau of Economic Research, Inc.

Hacioglu, S., D. Kanzig, And P. Surico (2020): "Consumption in the time of Covid-19: Evidence from UK Transaction Data," Centre for Economic Policy Research Paper Series 20-12.

Hall, R. E., C. I. Jones, And P. J. Klenow (2020): "Trading off Consumption and COVID-19 Deaths," Mimeo, Stanford University.

Hethcote, H. W. (2000): "The Mathematics of Infectious Diseases," SIAM Review, 42, 599-653. Hur, S. (2020): "The Distributional Effects of COVID-19 and Mitigation Policies," Working paper, Federal Reserve Bank of Dallas.

Jones, C. J., T. Philippon, And V. Venkateswaran (2020): "Optimal Mitigation Policies in a Pandemic: Social Distancing and Working from Home," Working Paper 26984, National Bureau of Economic Research.

Kaplan, G., B. Moll, and G. L. Violante (2018): "Monetary policy according to HANK," American Economic Review, 108, 697-743.

Kaplan, G. and G. L. Violante (2020): "The Marginal Propensity to Consume in Heterogeneous Agents Models," Working Paper. Princeton University.

Kaplan, G., G. L. Violante, And J. Weidner (2014): "The wealthy hand-to-mouth," Brookings Papers on Economic Activity, 139-153.

Kermack, W. O. And A. G. MCKendrick (1927): "A contribution to the mathematical theory of epidemics," Proceedings of the royal society of london. Series A, Containing papers of a mathematical and physical character, 115, 700-721.

Kniesner, T. J. And W. K. Viscusi (2019): "The Value of a Statistical Life," Forthcoming, 
Oxford Research Encyclopedia of Economics and Finance, 19-15.

Kozlowski, J., L. Veldkamp, and V. Venkateswaran (2020): "Scarring Body and Mind: The Long-Term Belief-Scarring E ects of COVID-19," Tech. rep.

Krueger, D., H. Uhlig, And T. Xie (2020): "Macroeconomic Dynamics and Reallocation in an Epidemic," PIER Working Paper Archive 20-015, Penn Institute for Economic Research, Department of Economics, University of Pennsylvania.

Lavetti, K. (2020): "The Estimation of Compensating Wage Differentials: Lessons From the Deadliest Catch," Journal of Business $\&$ Economic Statistics, 38, 165-182.

Liu, Y., A. A. Gayle, A. Wilder-Smith, and J. Rocklöv (2020): "The reproductive number of COVID-19 is higher compared to SARS coronavirus," Journal of travel medicine.

Mitze, T., R. Kosfeld, J. Rode, And K. Wälde (2020): "Face Masks Considerably Reduce COVID-19 Cases in Germany: A Synthetic Control Method Approach," IZA Discussion Papers 13319, Institute of Labor Economics (IZA).

Moll, B. (2020): "Lockdowns in SIR Models," Lecture Notes, available at https://benjaminmoll. com/SIR_notes/.

Mongey, S., L. Pilossoph, And A. Weinberg (2020): "Which Workers Bear the Burden of Social Distancing Policies?" NBER Working Papers 27085, National Bureau of Economic Research, Inc.

Moser, C. And P. Yared (2020): "Pandemic Lockdown: The Role of Government Commitment," MPRA Paper 99804, University Library of Munich, Germany.

Piguillem, F. And L. Shi (2020): "Optimal COVID-19 Quarantine and Testing Policies," EIEF Working Papers Series 2004, Einaudi Institute for Economics and Finance (EIEF).

RACHel, L. (2020): "An Analytical Model of Covid-19 Lockdowns," Tech. rep., Working Paper.

Tomer, A. And J. W. Kane (2020): "How to protect essential workers during COVID-19," Working Paper. Brookings Institution.

Toxvaerd, F. (2020): "Equilibrium Social Distancing," Tech. rep.

Vivalt, E. (2020): "SOC Codes for CISA Critical Infrastructure Workers," Working Paper. LMI Institute.

Wu, Z. And J. M. MCGoogan (2020): "Characteristics of and important lessons from the coronavirus disease 2019 (COVID-19) outbreak in China: summary of a report of 72314 cases from the Chinese Center for Disease Control and Prevention," Jama.

Zhou, F., T. Yu, R. Du, G. Fan, Y. Liu, Z. Liu, J. Xiang, Y. Wang, B. Song, X. Gu, ET AL. (2020): "Clinical course and risk factors for mortality of adult inpatients with COVID-19 in Wuhan, China: a retrospective cohort study," The Lancet. 